\title{
Microstructural Effects on Creep-Fatigue Life of Alloy 709
}

\author{
Project No.(s)
}

Michael McMurtrey, Laura Carroll, Jill Wright

The INL is a

U.S. Department of Energy

National Laboratory

operated by

Battelle Energy Alliance

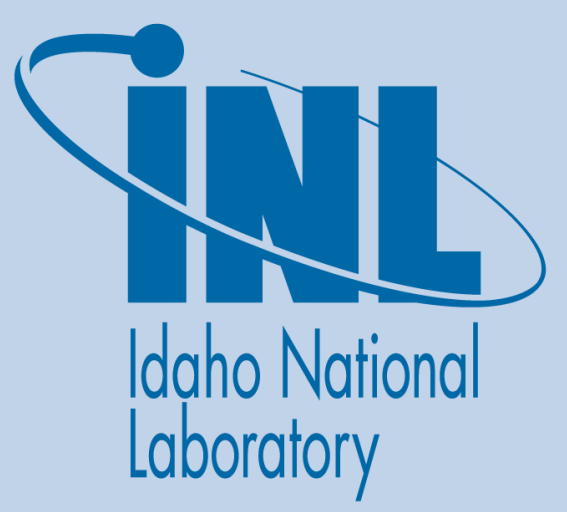

August 2017

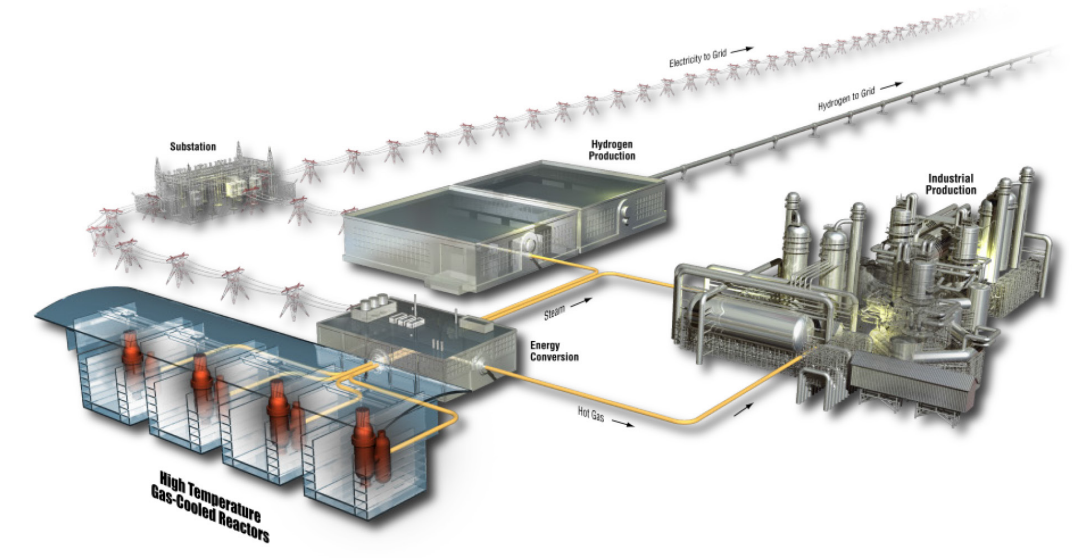




\section{DISCLAIMER}

This information was prepared as an account of work sponsored by an agency of the U.S. Government. Neither the U.S. Government nor any agency thereof, nor any of their employees, makes any warranty, expressed or implied, or assumes any legal liability or responsibility for the accuracy, completeness, or usefulness, of any information, apparatus, product, or process disclosed, or represents that its use would not infringe privately owned rights. References herein to any specific commercial product, process, or service by trade name, trade mark, manufacturer, or otherwise, does not necessarily constitute or imply its endorsement, recommendation, or favoring by the U.S. Government or any agency thereof. The views and opinions of authors expressed herein do not necessarily state or reflect those of the U.S. Government or any agency thereof. 
INL/EXT-17-41079

Revision 0

\section{Microstructural Effects on Creep-Fatigue Life of Alloy 709}

Michael McMurtrey, Laura Carroll, Jill Wright

August 2017

Idaho National Laboratory

INL ART TDO Program

Idaho Falls, Idaho 83415

http://www.inl.gov

Prepared for the

U.S. Department of Energy

Office of Nuclear Energy

Under DOE Idaho Operations Office

Contract DE-AC07-05ID14517 



\title{
INL ART TDO Program
}

\section{Microstructural Effects on Creep-Fatigue Life of Alloy 709}

\author{
INL/EXT-17-41079 \\ Revision 0
}

August 2017

Technical Reviewer: (Confirmation of mathematical accuracy, and correctness of data and appropriateness of assumptions.)

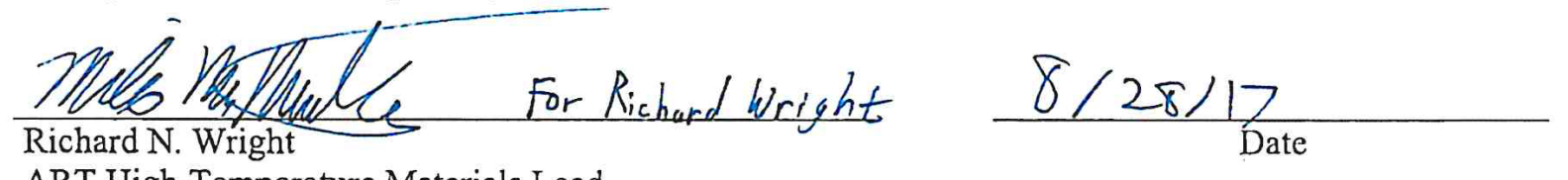

ART High-Temperature Materials Lead

Approved by:

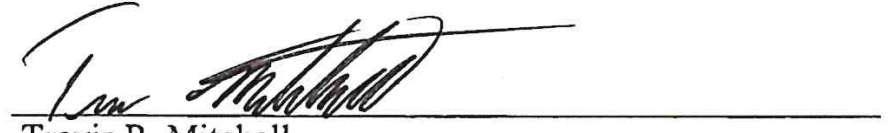

Travis R. Mitchell

ART TDO Project Manager

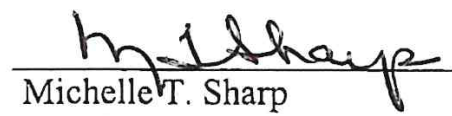

INL Quality Engineer

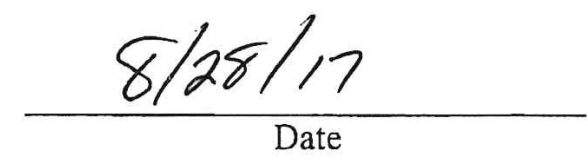

$8 / 28117$ 



\begin{abstract}
Creep-fatigue tests were performed on plates of Alloy 709 from various heats and processing conditions, but often with inhomogeneous microstructures. After testing, metallographic analysis was performed and the specimens were generally found to either have a uniform grain size or a bimodal grain size distribution with either isolated or groups (bands) of large grains. Creep-fatigue life was characterized with respect to the length of the grain boundary perpendicular to the stress axis, and it was found that large grains $(>400 \mu \mathrm{m})$ tended to be detrimental to creep-fatigue life, with the exception of elongated (parallel to the stress axis) grains and some specimens that underwent additional annealing.
\end{abstract}




\section{CONTENTS}

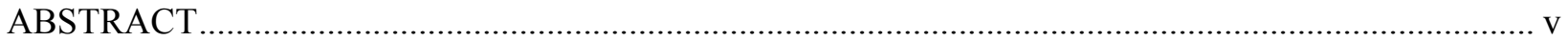

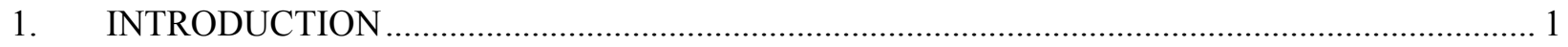

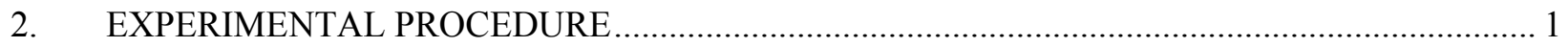

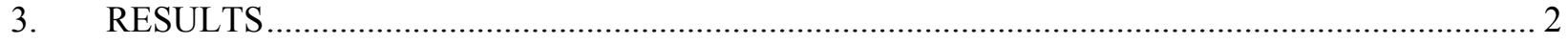

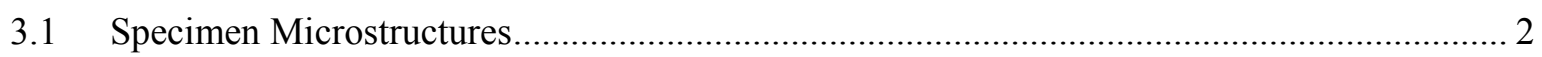

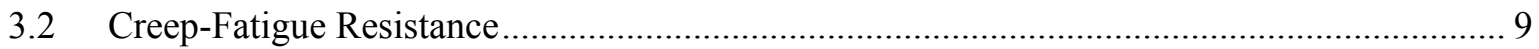

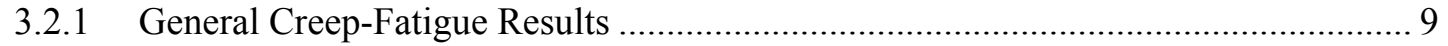

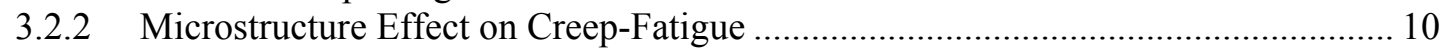

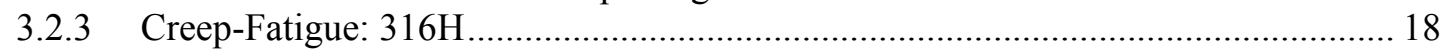

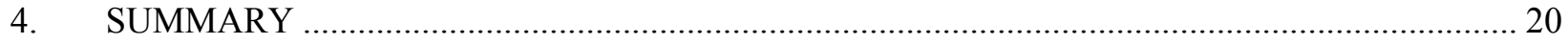

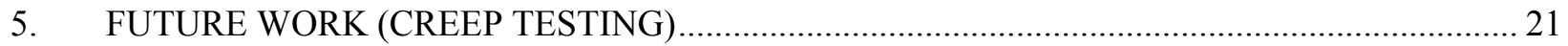

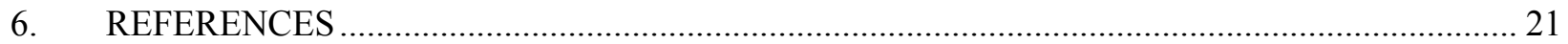

\section{FIGURES}

Figure 1. The deformed gauge sections of specimens showing presence of isolated large grains (indicated by arrows) within the Alloy 709 microstructure from (a) NF, (b) CPR, (c)

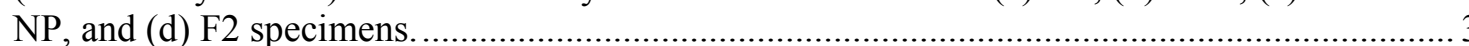

Figure 2. Banded regions of larger grains within the microstructure in the deformed gauge section of creep-fatigue specimens from specimens (a) 39A11-A, (b) 39A11-B, (c) 539-1, and (d) 539-2. The specimen axis is vertical and in the plane of the page for this and all of

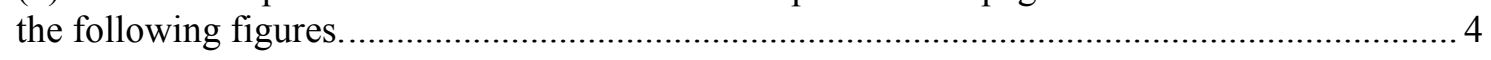

Figure 3. The gauge section showing the uniform grain structure in $\mathrm{H} 2$ specimens. ............................... 4

Figure 4. Typical microstructure within the grip section of specimen F1150-1 illustrating that large grains are predominant throughout the F1150 microstructure...........................................

Figure 5. The grip section of specimen H1150-1 illustrating that large grains are predominant throughout the H1150 material.

Figure 6. Optical images from creep-fatigue specimen (a) (b) NP-4 and (c) (d) NP-5 illustrating the presence of large grains.

Figure 7. Optical images from (a) the grip section of VE11-4 and (b) the gauge section of VE11-6 depicting a relatively uniform grain structure.

Figure 8. Plot of the number of cycles to failure $\left(\mathrm{N}_{\mathrm{f}}\right)$ as a function of hold time for fatigue and creep-fatigue of Alloy 709 and 316-type stainless steel. Note: All data within the box has a thirty minute hold time but is shifted along the x-axis to clearly depict all data points. "Trend" and QL3 data is included in the plot. The 316-type stainless steel (316, $316 \mathrm{~L}, 316 \mathrm{LN}, 316 \mathrm{FR})$ literature data ${ }^{10-18}$ is between the strain ranges of 0.96 and 
$1.04 \%$, temperatures from 600 to $700^{\circ} \mathrm{C}$, and tensile hold times of $0,10,30$, and 60 minutes.

Figure 9. Effect of large grain size (measured normal to the stress axis) effect on creep-fatigue life for Alloy 709 tested at $650^{\circ} \mathrm{C}$, with a $1 \%$ total strain and a 30 minute peak tension hold.

Figure 10. The deformed gauge section of creep-fatigue specimens (a) NF-7, (b) CPR-1, (c) NP-3, and (d) NP-6 illustrating the close proximity of a large grain or grains to the primary surface crack. The specimen axis in each of the images is vertical and in the plane of the page.

Figure 11 . The primary surface crack in the deformed gauge section of creep-fatigue specimen VE11-6.

Figure 12. The gauge section of cyclic test specimen VE11-4 illustrating a relatively large grain and interior cracking along the associated grain boundary......

Figure 13. Optical images of (a) interior grain boundary cracking and (b) (c) surface cracks from the deformed gauge section of creep-fatigue specimen type $\mathrm{H} 2$

Figure 14. Longitudinal cross-section from the gauge of deformed creep-fatigue specimen F2-3 illustrating (a) secondary surface cracks and (b) the primary surface crack, as well as the grain structure in the surrounding region.

Figure 15. An image of the longitudinal cross-section from the gauge of deformed creep-fatigue specimen F1150-1 (F2 with an additional high temperature secondary annealing) illustrating the intergranular nature of the crack initiation and propagation.

Figure 16. A more detailed breakdown of Figure 9, showing the size effect of the larger grains on creep-fatigue life. Specimens that underwent additional annealing are depicted separately, and the diameters both transverse and parallel to the stress axis are shown for specimens with elongated grains.

Figure 17. Micrographs from specimens (a) 539-2T-1, (b) 539-2T-2 and (c) 539-2T-3. Micrographs show cross sections of the gauge section post fatigue/creep-fatigue testing. Loading axis is vertical (up and down on the images)

Figure 18. Grain structure in the grip section of failed $316 \mathrm{H}$ creep-fatigue specimen $76 \mathrm{~B}-3$ illustrating larger grains with the grain structure. The largest grains are over $200 \mu \mathrm{m}$ in diameter.

Figure 19. Larger grains within a bimodal grain structure in the grip section of failed $316 \mathrm{H}$ creep-fatigue specimen 76B-4. The largest grains are over $200 \mu \mathrm{m}$ in diameter.

Figure 20. The microstructure and creep-fatigue cracking in a longitudinal cross-section of the gauge of $316 \mathrm{H}$ cyclic specimens (a) 76B-3 and (b) 76B-4, illustrating cracks that have propagated from the specimen surface.

\section{TABLES}

Table 1. Grain size analysis of Alloy 709 fatigue and creep-fatigue specimens. 


\section{Microstructural Effects on Creep-Fatigue Life of Alloy 709}

\section{INTRODUCTION}

Cyclic testing was carried out to characterize the fatigue and creep-fatigue behavior of Alloy 709 , an advanced austenitic structural alloy. The cyclic testing was conducted primarily at a single fatigue and creep-fatigue condition, which was at $650^{\circ} \mathrm{C}$ and $1.0 \%$ total strain $(+/-0.5 \%$ strain). For creep-fatigue, a 30 minute hold time at peak tensile strain was introduced. Specimens were machined from plates of several heats of Alloy 709, subjected to different processing conditions that resulted in varying, and sometimes inhomogeneous microstructures. In some cases the specimen microstructure varied with its location within the plate. The combined results of the cyclic testing and post-test metallographic characterization suggest that the microstructure, ultimately controlled by the processing conditions, has a limited influence on the Alloy 709 fatigue cycle life. In contrast, the presence of large grains may negatively impact the creep-fatigue resistance.

The number of cycles to failure $\left(\mathrm{N}_{\mathrm{f}}\right)$ at the selected creep-fatigue condition varied by up to a factor of five for the specimens tested. Specimens with an optimum microstructure, a uniform distribution of grains with diameters less than approximately $400 \mu \mathrm{m}$, resulted in a creep-fatigue resistance similar to that of 316-type stainless steel. The majority of the Alloy 709 cyclic test data was reported previously in milestone reports. ${ }^{1-4}$ The microstructural and processing details for the specific heats were reported by Yamamoto et al. ${ }^{58}$ This summary report includes creep-fatigue test results on three additional heats (Specimens referred to as F2, H2, and 539).

Although the specimen microstructure from multiple heats of Alloy 709 material has been inhomogeneous, general microstructural observations of the material have been characterized into three general regimes based on the presence of specific features:

1. Isolated large grains likely due to secondary recrystallization during final annealing.

2. Bands of large grains (non-recrystallized regions) due to incomplete recrystallization during final annealing.

3. A uniform grain structure.

The microstructures are generally a result of their processing history and fall into one of these general categories based on the combination of the amount of deformation during hot working and the annealing temperature. The microstructural inhomogeneity makes correlating the influence of these microstructural features to creep-fatigue resistance challenging.

\section{EXPERIMENTAL PROCEDURE}

Creep-fatigue testing at $650^{\circ} \mathrm{C}$, primarily at $1.0 \%$ total strain and a 30 minute peak tensile strain hold, was conducted on specimens from small to intermediate-sized Alloy 709 heats. Fully reversed, strain-controlled low-cycle triangular waveform fatigue and creep-fatigue testing was conducted at a strain rate of $10^{-3} / \mathrm{s}$ in laboratory air using servo-hydraulic test frames in accordance with PLN-3346. ${ }^{9}$ In all cases, the Alloy 709 material was received from Oak Ridge National Laboratory (ORNL). The creep-fatigue tests followed a similar waveform as the standard fatigue test, with the addition of a strain-controlled hold time at peak tensile strain. The $\mathrm{N}_{\mathrm{f}}$ is defined as a decrease in the peak tensile stress of $25 \%$ from the point at which the peak stress initially deviates from a steadily declining value. 
Selected fatigue and creep-fatigue specimens were prepared for metallurgical analysis after testing. For evaluation, the gauge sections of the cyclically deformed specimens were cut in half along the stress axis. The location for the longitudinal slice was selected such that the cut surface captured the largest visible surface crack. The exposed face was then fixed in a metallographic mount, polished, and etched to reveal microstructural features. Microscopy was conducted using a Zeiss Axio Observer Z1m and a Keyence VHX-6000 optical microscopes. In some cases, the metallographic mount encompassed most of the gauge section length; while in others, only one side of the fractured gauge section was included.

Due to the bimodal distribution of grain sizes in many specimens, the grains were measured in the optical micrographs and based on their size categorized as either large or small grains. Grain sizes were determined for the large and small grain sizes by averaging the measurements of a large number of each grain type separately. In the case of specimens containing elongated grains, the grain diameter or length along the axes perpendicular and parallel to the stress axis were measured and reported separately.

\section{RESULTS}

\subsection{Specimen Microstructures}

The specimen microstructures are generally the result of processing conditions and fall into three general categories based on the presence of specific features, although significant inhomogeneity exists:

1. Isolated large grains likely due to secondary recrystallization during final annealing.

2. Bands of large grains (non-recrystallized regions) due to incomplete recrystallization during final annealing.

3. A uniform grain structure.

Examples of optical metallography from the gauge section of cyclic test specimens are shown for each type of microstructure. Figure 1 provides images of microstructures where isolated large grains exist. In some specimens, only a single large grain was found to exist in the examined specimen cross-section, though the size difference is usually significant (in one specimen, a single large grain, measuring $1200 \mu \mathrm{m}$ in diameter was found where otherwise, the average grains size was $55 \mu \mathrm{m}$ ). Microstructures revealing banded regions consisting of larger grains are shown in Figure 2. An optical image showing an example of a uniform grain structure is shown in Figure 3.

In some specimens, the grains are elongated, as seen in Figure 1(d) and Figure 2(a)-(c). In general, the elongated axis of the non-recrystallized grains was aligned with the specimen axis and thus the stress axis, with the grains measuring $100-300 \mu \mathrm{m}$ perpendicular to the specimen axis and $600-1000 \mu \mathrm{m}$ parallel to the specimen axis. This is an important distinction as cracks initiate and propagate perpendicular to the stress axis, along the shorter contiguous grain boundary distance. The large grain boundary length along the stress axis is not expected to have a strong effect on the creep-fatigue life. Specimens tested in the transverse orientation would tend to have cracks propagate along the longer grain boundary expanses, which is expected to be detrimental to the creep-fatigue, and potentially fatigue, resistance.

An additional higher temperature annealing conducted at ORNL of sections of material from heats F2 and $\mathrm{H} 2$ resulted in grain structures that primarily consisted of very large diameter grains, as shown for F1150 and H1150 in Figure 4 and Figure 5, respectively. In both of these materials, grain diameters of greater than $350 \mu \mathrm{m}$ were frequently observed and are clearly substantially larger than those of material without the additional annealing treatment (H2 shown in Figure 3). Based on the dramatically larger grains, it is likely that extensive secondary recrystallization has occurred. 


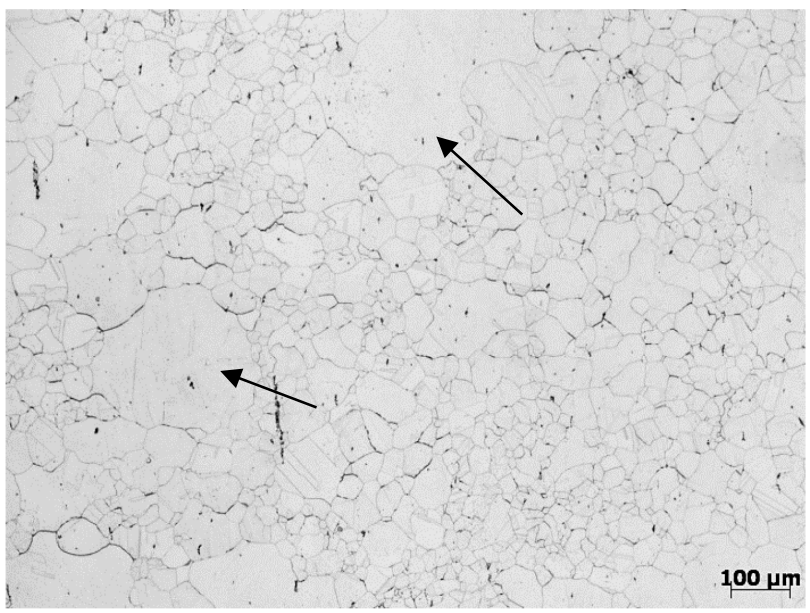

(a)

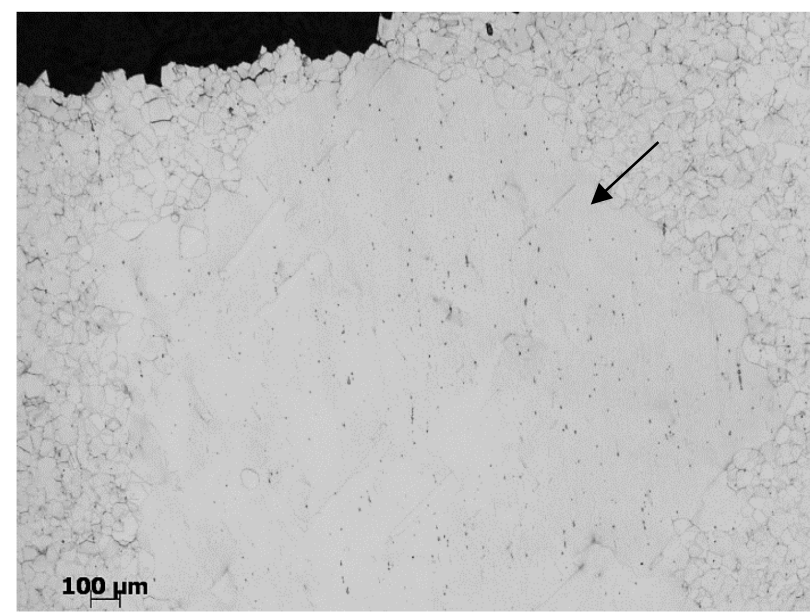

(c)

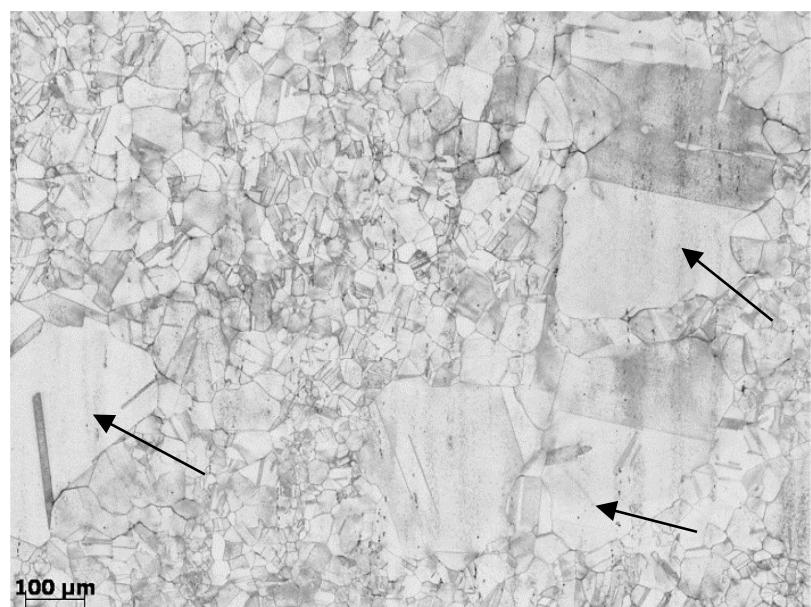

(b)

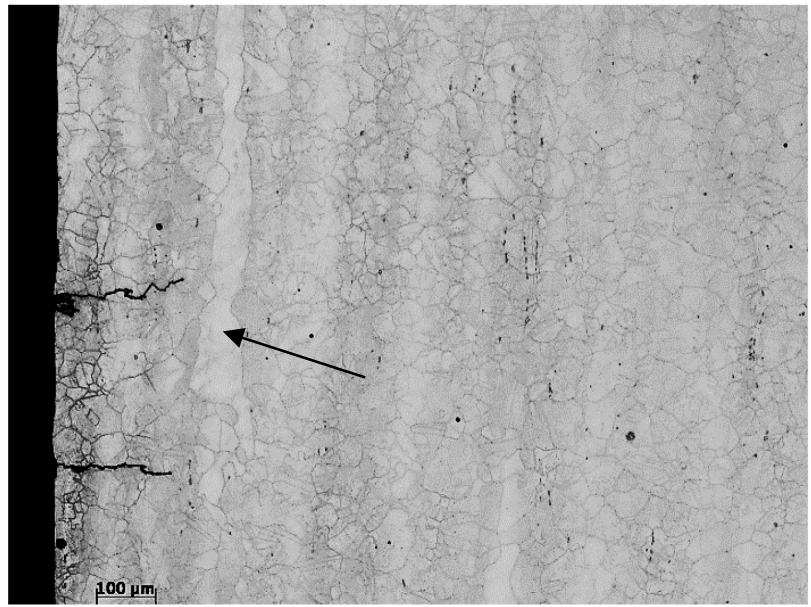

(d)

Figure 1. The deformed gauge sections of specimens showing presence of isolated large grains (indicated by arrows) within the Alloy 709 microstructure from (a) NF, (b) CPR, (c) NP, and (d) F2 specimens. 


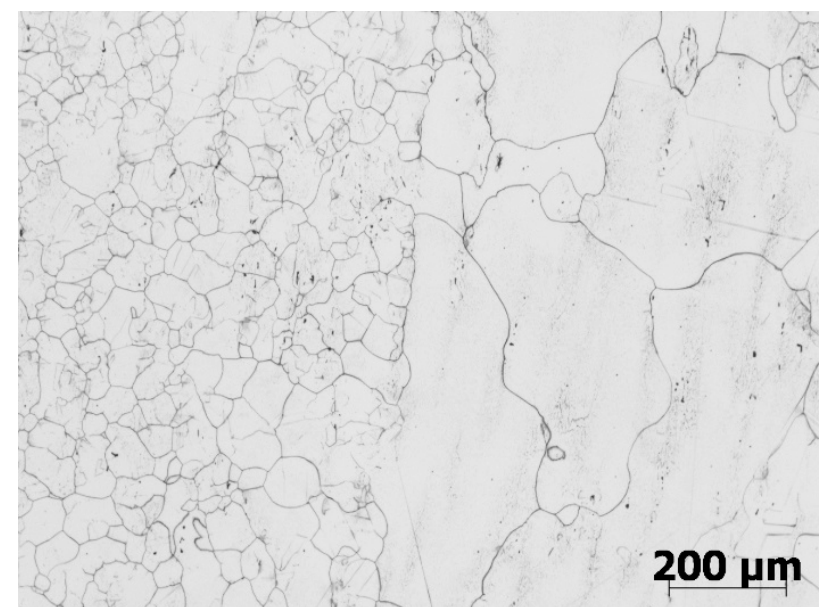

(a)

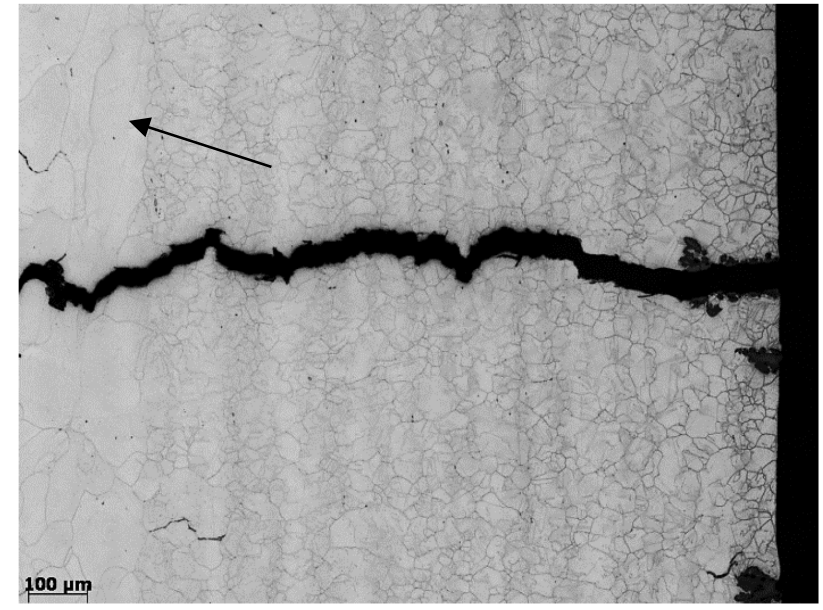

(c)

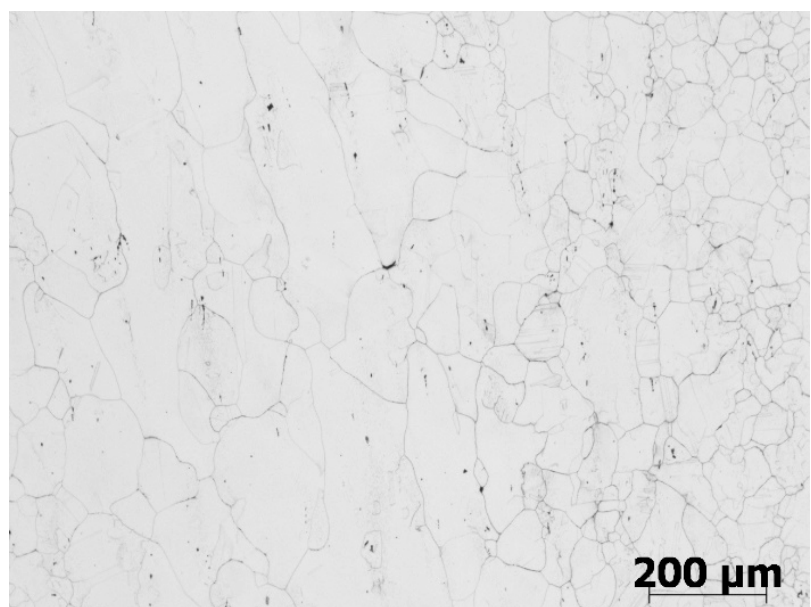

(b)

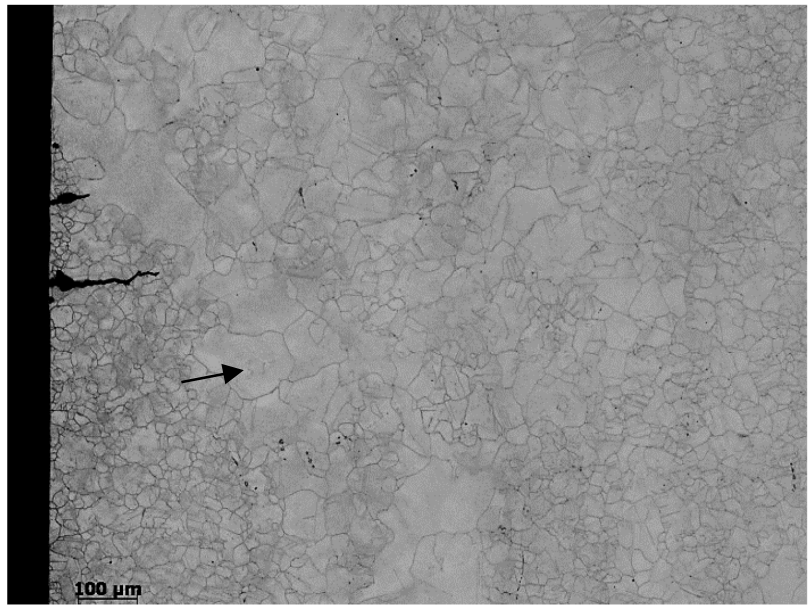

(d)

Figure 2. Banded regions of larger grains within the microstructure in the deformed gauge section of creep-fatigue specimens from specimens (a) 39A11-A, (b) 39A11-B, (c) 539-1, and (d) 539-2. The specimen axis is vertical and in the plane of the page for this and all of the following figures.

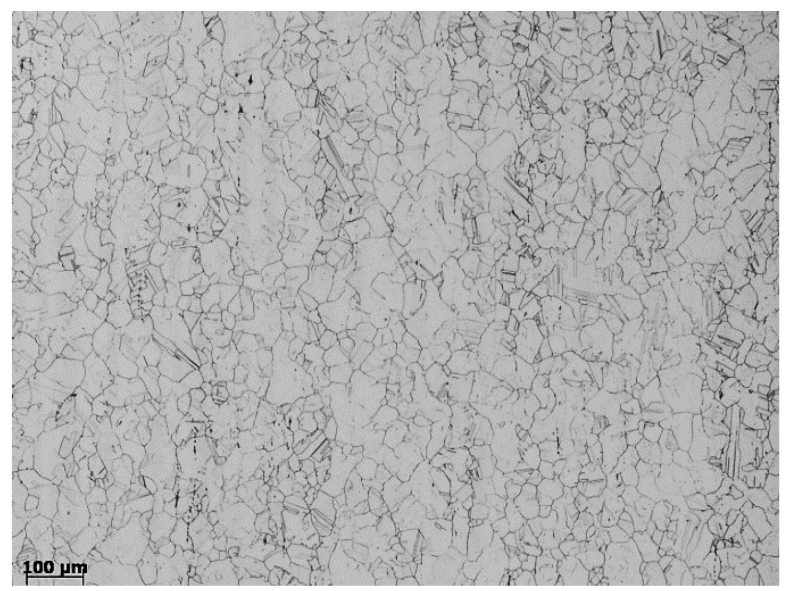

Figure 3. The gauge section showing the uniform grain structure in $\mathrm{H} 2$ specimens. 


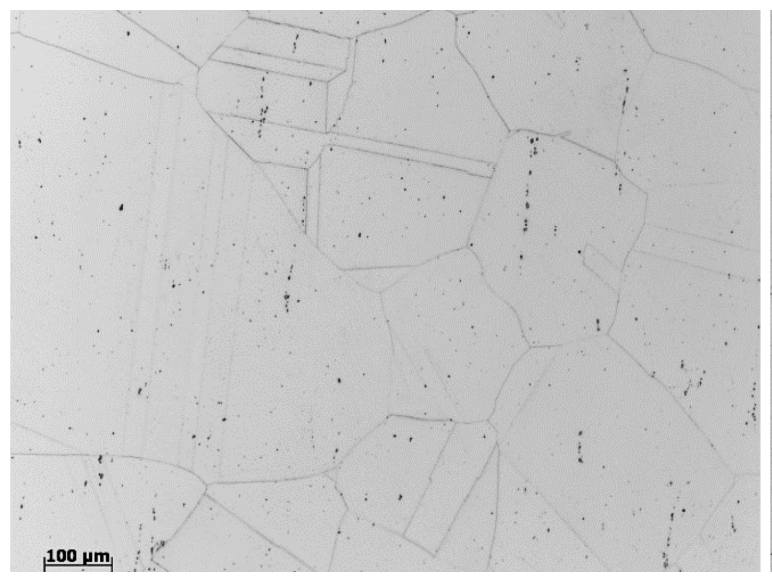

(a)

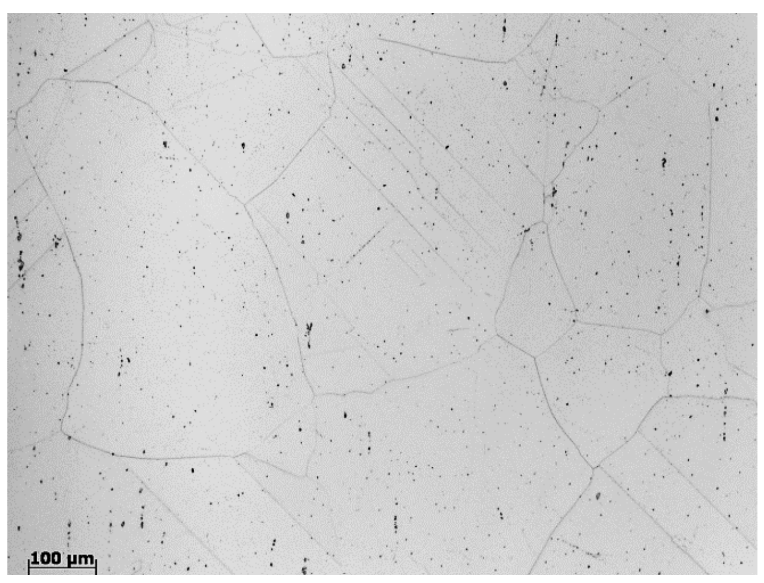

(b)

Figure 4. Typical microstructure within the grip section of specimen F1150-1 illustrating that large grains are predominant throughout the F1150 microstructure.

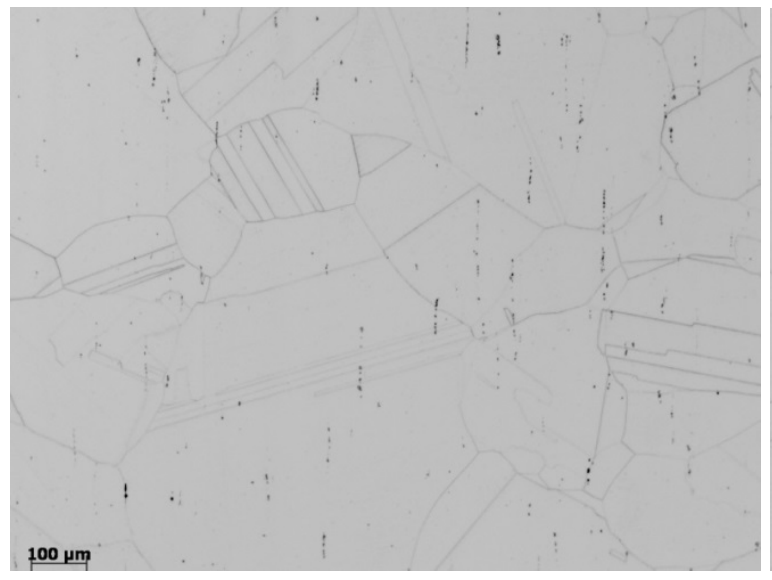

(a)

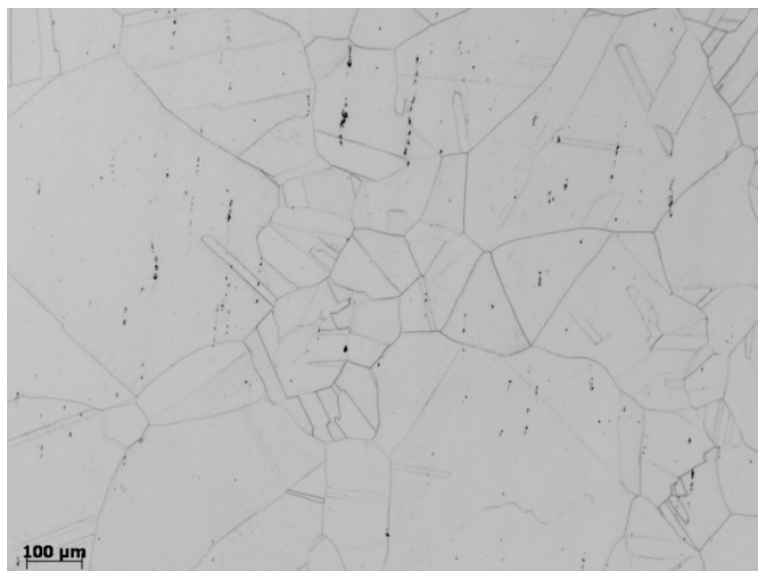

(b)

Figure 5. The grip section of specimen H1 150-1 illustrating that large grains are predominant throughout the H1150 material.

The NP and VE11 specimens were cut from the same heat and exhibited the largest diameter isolated grains, measuring 1000-2000 $\mu \mathrm{m}$. Two sections of this material were given an additional annealing treatment at temperatures lower than the original final annealing temperature: test specimens NP-4 and NP-5, prior to creep-fatigue testing (Figure 6), and a portion of plate was annealed to a higher temperature prior to machining specimens VE11-4 and VE11-6 from this plate (Figure 7). These lower temperature anneals were not expected to have changed the grain structure. Differences in grain structure are difficult to attribute to annealing due to grain structure inhomogeneity within a plate. However, the phase fractions, as well as precipitate sizes and distributions, likely did change. 


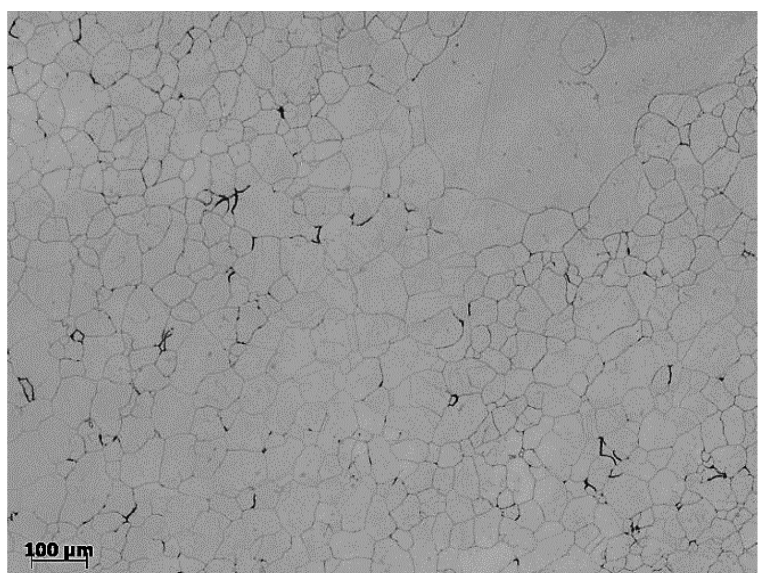

(a)

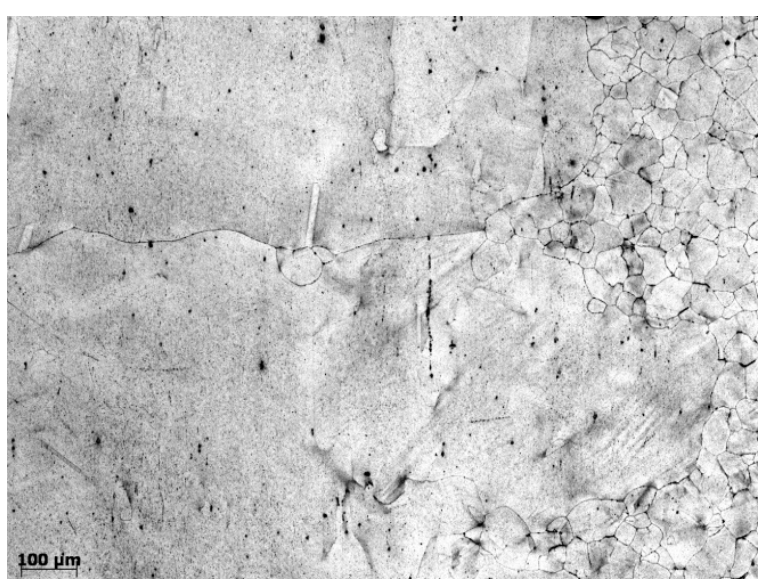

(c)

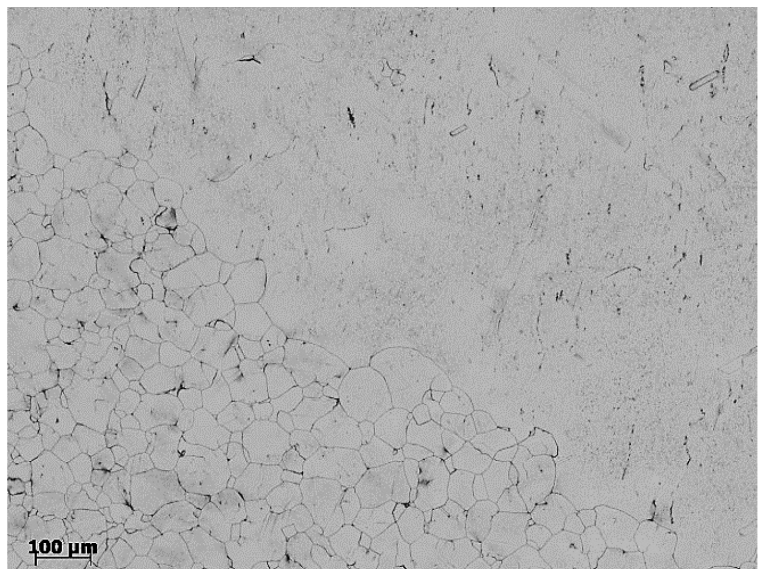

(b)

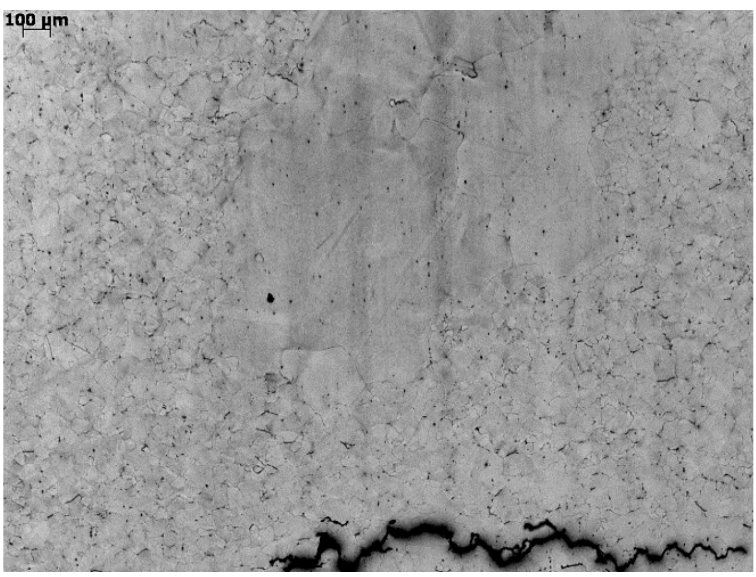

(d)

Figure 6. Optical images from creep-fatigue specimen (a) (b) NP-4 and (c) (d) NP-5 illustrating the presence of large grains.

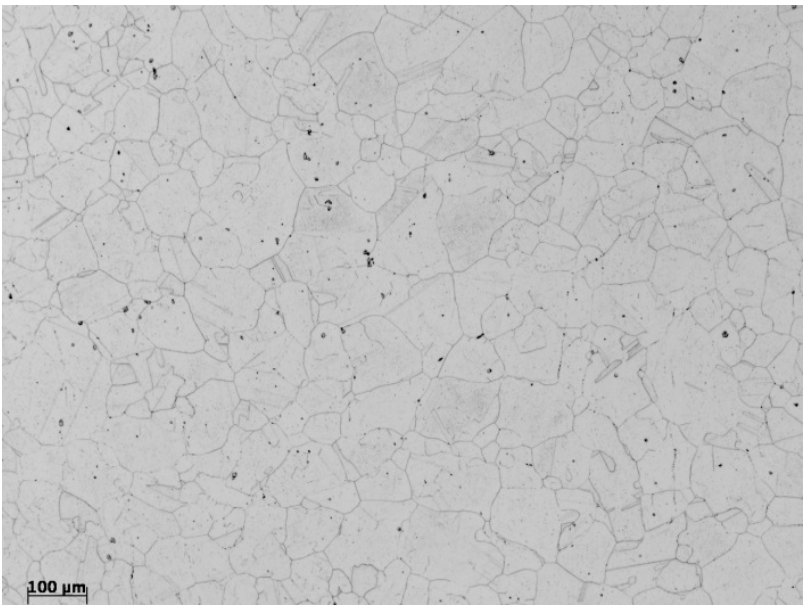

(a)

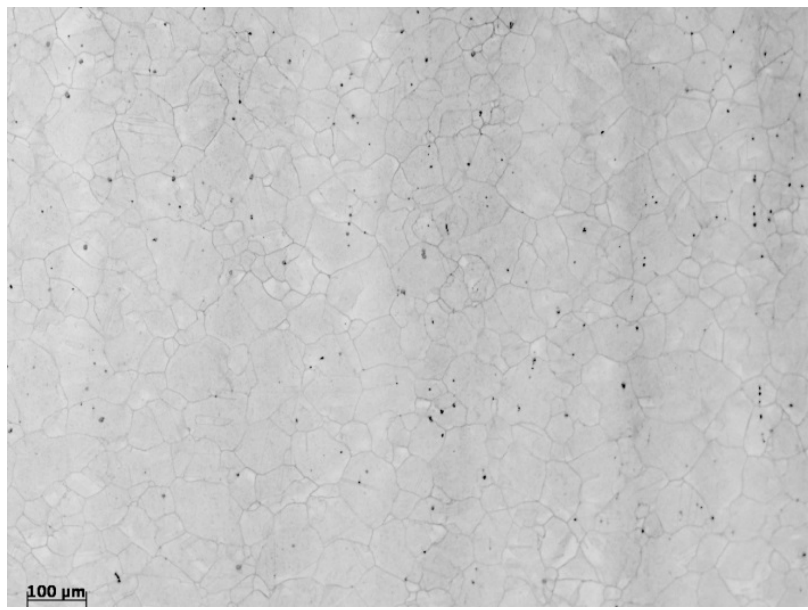

(b)

Figure 7. Optical images from (a) the grip section of VE11-4 and (b) the gauge section of VE11-6 depicting a relatively uniform grain structure. 
Results of the grain size measurements are provided in Table 1. Grain size measurements were taken along both the tensile axis and transverse axis, though in cases where difference in sizes of the two axes measured less than $50 \mu \mathrm{m}$, the grains were considered equiaxed and only one size was reported.

Table 1. Grain size analysis of Alloy 709 fatigue and creep-fatigue specimens.

\begin{tabular}{|c|c|c|c|}
\hline Specimen ID & $\begin{array}{c}\text { Small grain size } \\
(\mu \mathrm{m})\end{array}$ & $\begin{array}{c}\text { Large grain- } \\
\text { transverse axis } \\
(\mu \mathrm{m})\end{array}$ & $\begin{array}{c}\text { Avg. Large grain- } \\
\text { tensile axis }(\mu \mathrm{m})\end{array}$ \\
\hline NF-3 & \multicolumn{3}{|c|}{ Not measured } \\
\hline NF-4 & \multicolumn{3}{|c|}{ Not measured } \\
\hline NF-1 & 32 & 120 & - \\
\hline NF-2 & 24 & 145 & - \\
\hline NF-5 & 30 & 265 & 350 \\
\hline NF-6 & 38 & 70 & - \\
\hline NF-7 & 47 & 88 & - \\
\hline NF-8 & 30 & 100 & - \\
\hline NF-9 & 35 & 121 & - \\
\hline CPR-6 & \multicolumn{3}{|c|}{ Not measured } \\
\hline CPR-9 & \multicolumn{3}{|c|}{ Not measured } \\
\hline CPR-11 & \multicolumn{3}{|c|}{ Not measured } \\
\hline CPR-1 & 34 & 232 & - \\
\hline CPR-12 & 49 & 467 & 581 \\
\hline CPR-13 & 50 & 300 & - \\
\hline CPR-2 & 33 & 126 & - \\
\hline CPR-3 & 35 & 192 & - \\
\hline CPR-4 & 42 & 186 & - \\
\hline CPR-5 & \multicolumn{3}{|c|}{ Not measured } \\
\hline CPR-7 & 50 & 150 & - \\
\hline CPR-8 & 37 & 176 & - \\
\hline NP-2 & 46 & - & - \\
\hline NP-8 & 77 & 895 & 1367 \\
\hline NP-9 & - & - & - \\
\hline NP-1 & 107 & 1115 & 1314 \\
\hline NP-3 & 37 & 124 & - \\
\hline NP-6 & 85 & 1345 & 1179 \\
\hline NP-7 & 73 & 1093 & 1225 \\
\hline NP-4 & 22 & 1540 & 2299 \\
\hline NP-5 & 50 & 1500 & - \\
\hline VE11-4 & 45 & 220 & - \\
\hline VE11-6 & 43 & 130 & - \\
\hline 39A11-A-1 & \multicolumn{3}{|c|}{ Not measured } \\
\hline 39A11-A-2 & 55 & 409 & 559 \\
\hline 39A11-A-6 & 62 & 291 & 356 \\
\hline
\end{tabular}


Table 1. (continued).

\begin{tabular}{|c|c|c|c|}
\hline Specimen ID & $\begin{array}{c}\text { Small grain size } \\
(\mu \mathrm{m})\end{array}$ & $\begin{array}{c}\text { Large grain- } \\
\text { transverse axis } \\
(\mu \mathrm{m})\end{array}$ & $\begin{array}{c}\text { Avg. Large grain- } \\
\text { tensile axis }(\mu \mathrm{m})\end{array}$ \\
\hline 39A11-B-1 & \multicolumn{3}{|c|}{ Not measured } \\
\hline 39A11-B-5 & \multicolumn{3}{|c|}{ Not measured } \\
\hline 39A11-B-2 & \multicolumn{3}{|c|}{ Not measured } \\
\hline 39A11-B-3 & \multicolumn{3}{|c|}{ Not measured } \\
\hline 39A11-B-4 & 51 & 262 & 379 \\
\hline 39X11-B-1 & \multicolumn{3}{|c|}{ Not measured } \\
\hline $39 X 11-B-5$ & \multicolumn{3}{|c|}{ Not measured } \\
\hline $39 \times 11-B-2$ & \multicolumn{3}{|c|}{ Not measured } \\
\hline $39 X 11-B-3$ & 135 & 379 & 755 \\
\hline 40A21-A-1 & \multicolumn{3}{|c|}{ Not measured } \\
\hline 40A21-A-4 & \multicolumn{3}{|c|}{ Not measured } \\
\hline 40A21-A-2 & 33 & 165 & - \\
\hline 40A21-A-5 & \multicolumn{3}{|c|}{ Not measured } \\
\hline 40A21-B-1 & \multicolumn{3}{|c|}{ Not measured } \\
\hline 40A21-B-5 & \multicolumn{3}{|c|}{ Not measured } \\
\hline 40A21-B-2 & 28 & 179 & - \\
\hline 40A21-B-7 & 28 & 220 & - \\
\hline $40 \times 21-B-1$ & \multicolumn{3}{|c|}{ Not measured } \\
\hline $40 \times 21-B-5$ & \multicolumn{3}{|c|}{ Not measured } \\
\hline $40 \times 21-B-4$ & \multicolumn{3}{|c|}{ Not measured } \\
\hline $40 \times 21-B-7$ & \multicolumn{3}{|c|}{ Not measured } \\
\hline F2-4 & \multicolumn{3}{|c|}{ Not measured } \\
\hline F2-7 & \multicolumn{3}{|c|}{ Not measured } \\
\hline $\mathrm{F} 2-3$ & 47 & 90 & 700 \\
\hline F1150-1 & 500 & & - \\
\hline $\mathrm{H} 2-7$ & \multicolumn{3}{|c|}{ Not measured } \\
\hline $\mathrm{H} 2-5$ & 27 & 119 & - \\
\hline H1150-1 & 200 & 600 & - \\
\hline H1150-2 & 250 & 600 & - \\
\hline H1150-4 & \multicolumn{3}{|c|}{ Not measured } \\
\hline $5391-1$ & 22 & 143 & 400 \\
\hline $5391-2$ & 24 & - & - \\
\hline $5392-1$ & 25 & 200 & 400 \\
\hline $5392-2$ & 57 & 149 & 1000 \\
\hline $539-2 \mathrm{~T}-3$ & \multicolumn{3}{|c|}{ Not measured } \\
\hline $539-2 \mathrm{~T}-1$ & \multicolumn{3}{|c|}{ Not measured } \\
\hline $539-2 \mathrm{~T}-2$ & \multicolumn{3}{|c|}{ Not measured } \\
\hline $539-2 \mathrm{~T}-4$ & \multicolumn{3}{|c|}{ Not measured } \\
\hline
\end{tabular}




\subsection{Creep-Fatigue Resistance}

The scatter in the creep-fatigue life was larger than expected, and so a more in-depth study was undertaken to examine the effects of grain structure on creep-fatigue life. Taken in whole, the creep-fatigue behavior from Alloy 709 with various microstructures suggests that the presence of very large grains is likely detrimental to the creep-fatigue resistance. A definitive correlation, however, is difficult to ascertain due to the microstructural inhomogeneity across a given heat/plate and the variability inherent to creep-fatigue testing. Initially, the specimen locations within a given plate were not tracked and the plate microstructures were not examined. The degree of the microstructural variation was recognized after testing the first three heats, all of which exhibited some secondary recrystallization.

To determine if the specimen grain structure correlates to $\mathrm{N}_{\mathrm{f}}$, grain structures in the gauge section of most of the tested creep-fatigue specimens were studied. This correlation between the microstructural features and the regimes is based on the work of Yukinori Yamamoto. ${ }^{8}$ However, the grain measurements were not extensive and a more thorough analysis to enhance the correlation would require analysis of the full gauge section region and a three dimensional characterization, either through multiple cross-sectional metallographic mounts or x-ray analysis. Additional work is also needed to confirm the cause of these microstructures as secondary recrystallization and incomplete recrystallization.

\subsubsection{General Creep-Fatigue Results}

Typically, scatter in the number of creep-fatigue cycles to failure is less than a factor of two for a given material condition; more than this implies a material difference. The scatter in creep-fatigue cycles to failure for the Alloy 709 plates is over a factor of five as depicted by the colored data points in Figure 8. Literature values ${ }^{10} 18$ of the creep-fatigue cycles to failure for 316 stainless steel $(316,316 \mathrm{~L}$, $316 \mathrm{LN}$, and $316 \mathrm{FR}$ ) at temperatures between 600 and $700^{\circ} \mathrm{C}$ and at strain ranges between 0.96 and $1.04 \%$ with tensile hold times of 0, 10, 30 and 60 minutes are included as black data points in Figure 8 for comparison. 


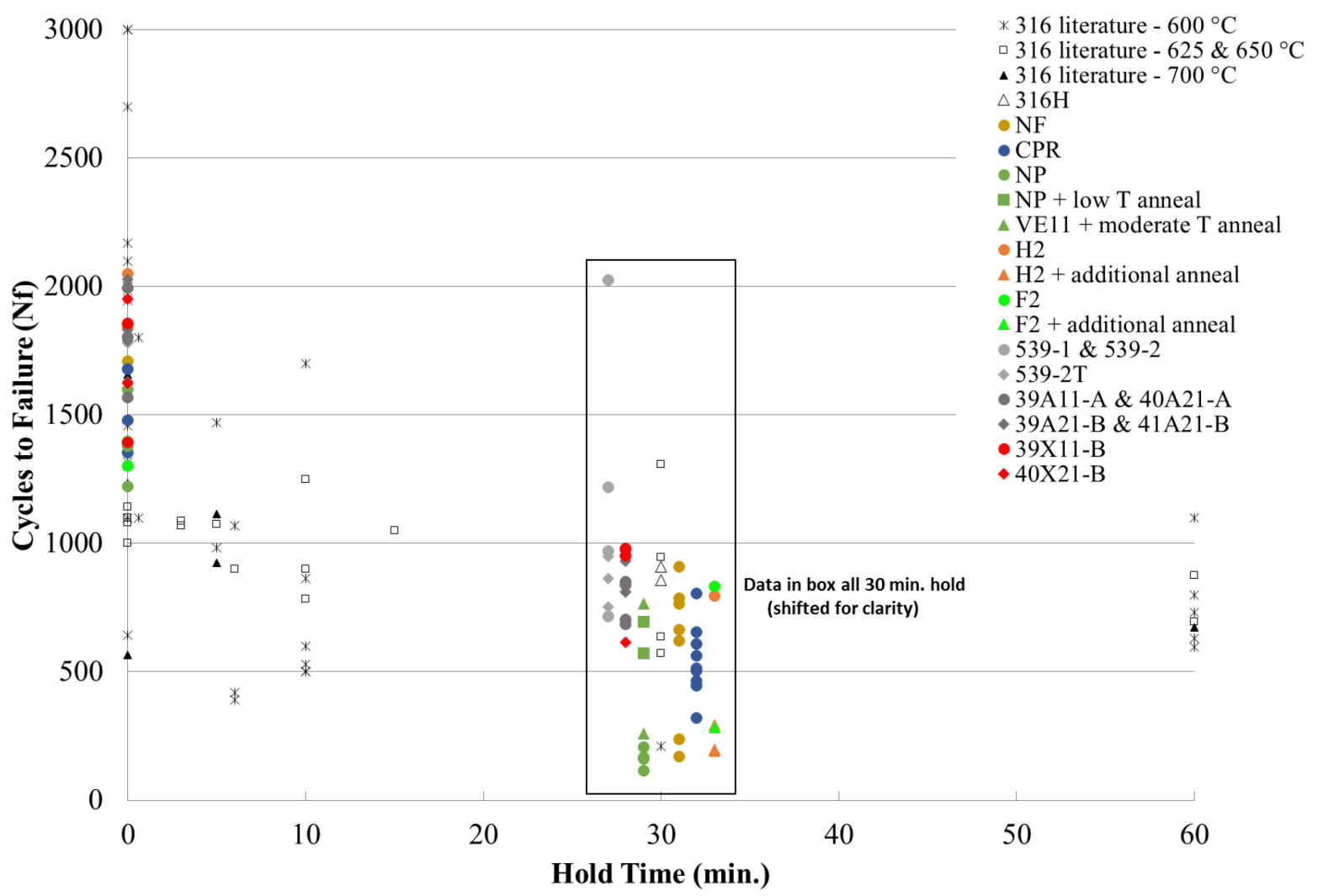

Figure 8. Plot of the number of cycles to failure $\left(\mathrm{N}_{\mathrm{f}}\right)$ as a function of hold time for fatigue and creepfatigue of Alloy 709 and 316-type stainless steel. Note: All data within the box has a thirty minute hold time but is shifted along the x-axis to clearly depict all data points. "Trend" and QL3 data is included in the plot. The 316-type stainless steel $(316,316 \mathrm{~L}, 316 \mathrm{LN}, 316 \mathrm{FR})$ literature data ${ }^{10-18}$ is between the strain ranges of 0.96 and $1.04 \%$, temperatures from 600 to $700^{\circ} \mathrm{C}$, and tensile hold times of $0,10,30$, and 60 minutes.

\subsubsection{Microstructure Effect on Creep-Fatigue}

In general, a trend has been observed of decreasing creep-fatigue life in the presence of large grains, as shown in Figure 9, which shows the measurements of the larger grains of each specimen compared to creep-fatigue life. Grains $>400 \mu \mathrm{m}$ (measured in the axis transverse to the stress axis) appear to be the threshold where grain size detrimentally affects creep-fatigue life. Individual data points will be discussed in more detail in the following paragraphs. 


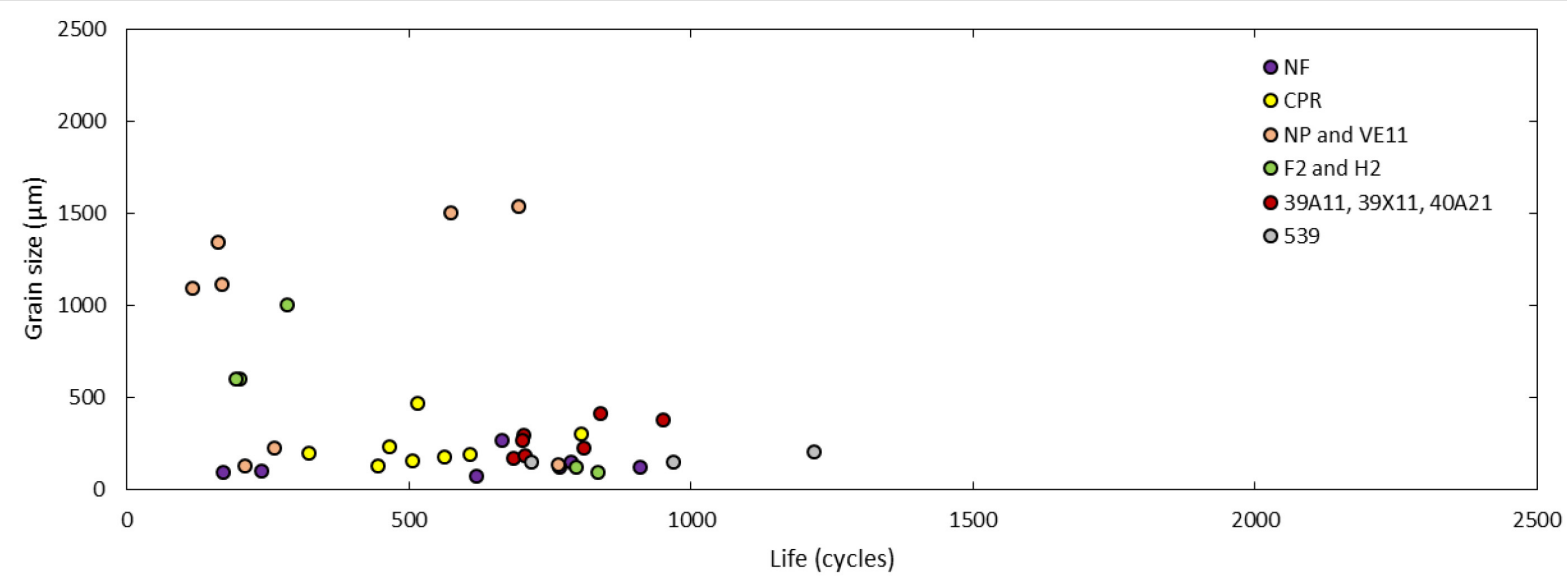

Figure 9. Effect of large grain size (measured normal to the stress axis) effect on creep-fatigue life for Alloy 709 tested at $650^{\circ} \mathrm{C}$, with a $1 \%$ total strain and a 30 minute peak tension hold.

Initial testing found that the NF specimens (dark purple data points in Figure 9) exhibited $\mathrm{N}_{\mathrm{f}}$ in the range of $\sim 600$ to 950 (large grain sizes between 120 - $200 \mu \mathrm{m}$ ); however, subsequent testing resulted in two specimens with substantially reduced cycle lives closer to 200 cycles (large grain sizes of 300 and $75 \mu \mathrm{m})$. The data is considered "trend" because failure occurred opposite the upper extensometer contact point. ${ }^{3}$ It is unclear whether these creep-fatigue results are representative and the result of larger isolated grains, shown in Figure 1(a). Evidence of enlarged, isolated grains near a surface crack are shown in Figure 10(a).

Creep-fatigue testing of the CPR specimens, which clearly has isolated larger grains (Figure 1(b), large grain sizes $150-350 \mu \mathrm{m}$ ), consistently exhibited a relatively low $\mathrm{N}_{\mathrm{f}}$, ranging from $\sim 300$ to 650 . Figure 10(b) shows an example of larger grains around the surface crack in a tested CPR creep-fatigue specimen, CPR-1. Similarly, the creep-fatigue resistance of the NP and VE11 material (NP and VE11 originated from the same heat) was degraded, with the $\mathrm{N}_{\mathrm{f}}$ ranging from $\sim 100$ to 200. Metallography from the gauge section of NP-3 and NP-6, as shown in Figure 10(c) and (d), revealed very large grains (1000$1200 \mu \mathrm{m})$ near the surface that likely influenced the initiation of the primary crack.

Microstructural analysis of NF, CPR, and NP/VE11 specimens supports the hypothesis that large grains are detrimental to the creep-fatigue resistance based upon their often observed presence near a primary surface crack in the specimens with a reduced $\mathrm{N}_{\mathrm{f}}$. However, this is not always the case, for example NF-7, NF-8, CPR-3 and VE11-4 exhibited short fatigue lives despite no visible large grains in the cross section. This may be due to the cross-section giving a single layer, two-dimensional view of the microstructure and not a full characterization through the thicknesses of the specimens.

The two specimens of NP material went through as second, additional anneal at a low temperature, NP-4 and NP-5 (large grain sizes 1300 and $1500 \mu \mathrm{m}$ ). They exhibited a significantly higher $\mathrm{N}_{\mathrm{f}}$ either because of a variation in the local grain structure or perhaps because grain boundary carbides promoted by the lower temperature anneal offer improved resistance to cracking. Large grains were observed in metallographic mounts from the NP-4 and NP-5 specimens, as shown in Figure 6. Despite the presence of large grains in the local specimen microstructure, large grains were not observed in the single crosssection near the primary surface crack of either specimen, and the primary crack propagation path was not intergranular. This change in crack path mode is indicative of grain boundary carbides improving the resistance to grain boundary cracking. 


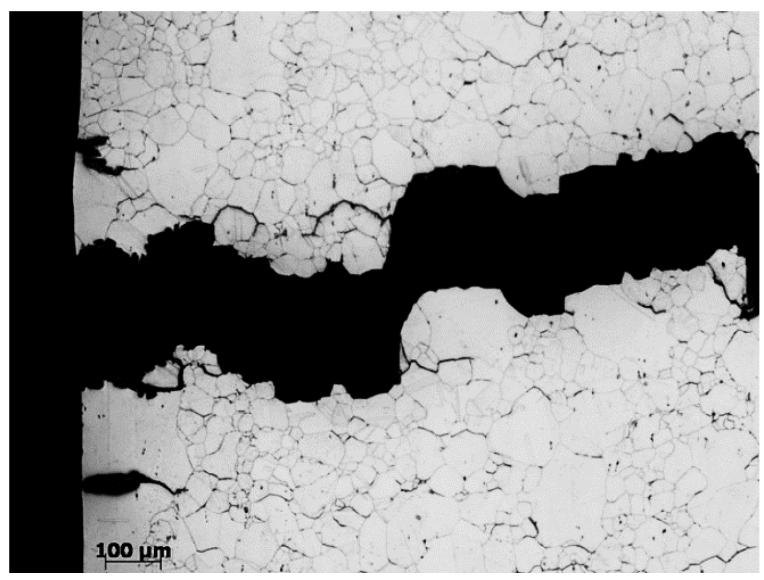

(a)

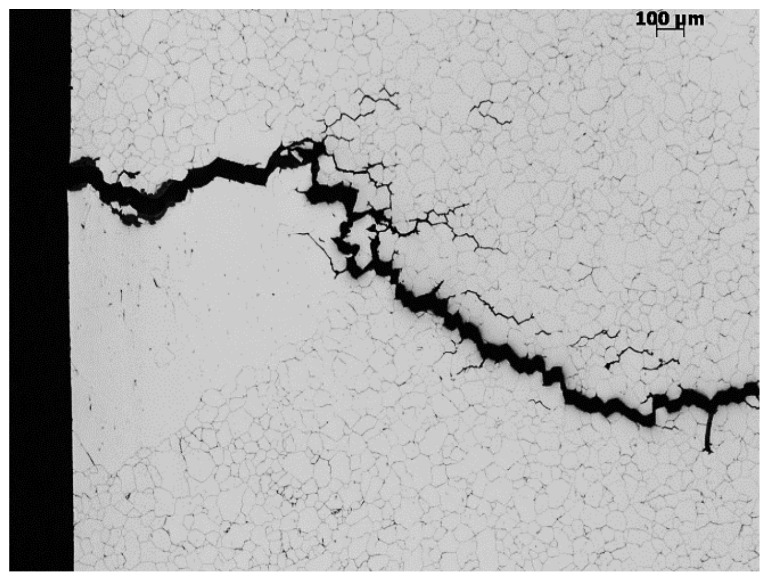

(c)

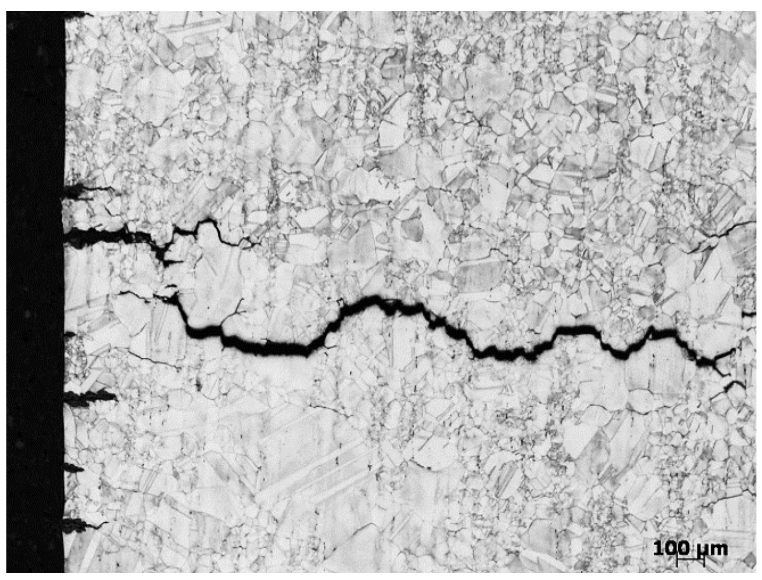

(b)

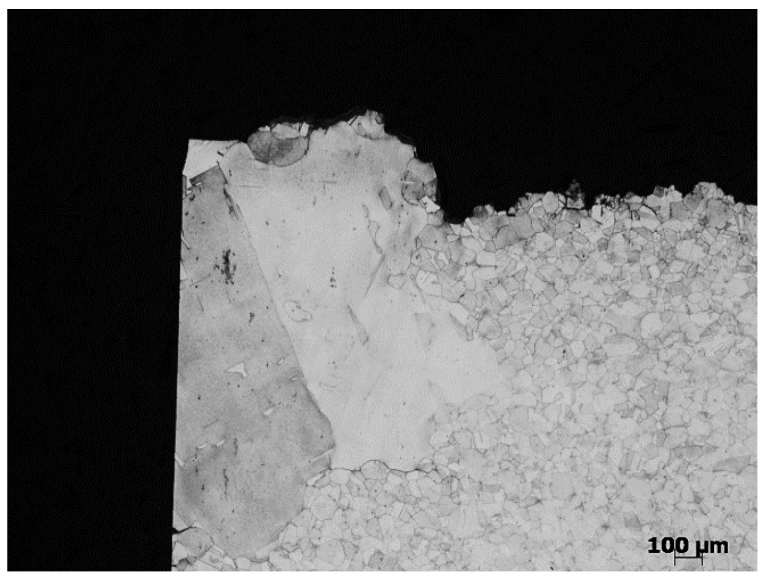

(d)

Figure 10. The deformed gauge section of creep-fatigue specimens (a) NF-7, (b) CPR-1, (c) NP-3, and (d) NP-6 illustrating the close proximity of a large grain or grains to the primary surface crack. The specimen axis in each of the images is vertical and in the plane of the page.

The creep-fatigue results from the VE11 specimens, with a moderate temperature secondary anneal, are more difficult to interpret. One specimen, VE11-6 (large grain size of $130 \mu \mathrm{m}$ ), failed at a relatively high $\mathrm{N}_{\mathrm{f}}$, and a second specimen, VE11-4 (large grain size of $180 \mu \mathrm{m}$ ), failed at a relatively low $\mathrm{N}_{\mathrm{f}}$. A metallographic cross-section of the VE11-6 gauge length did not reveal the presence of any large, isolated grains (Figure 7(b)). An image of the primary crack and the surrounding microstructure in VE11-6 is shown in Figure 11. The crack appears to propagate in a mixed-mode with the crack advancing transgranularly in some regions and intergranularly in others. Though rare, grains larger than $200 \mu \mathrm{m}$ were observed in the gauge section of the VE11-4 specimen as shown in Figure 12, which shows a grain of approximately $300 \mu \mathrm{m}$ in diameter adjacent to the crack path. The grain structure imaged in the grip section of these VE11 specimens after cycling appears relatively uniform and equiaxed without the presence of extremely large grains (Figure 7), in contrast to the NP specimens (originating from the same heat) without the secondary annealing treatment (Figure 1 (c)). This variation is most likely attributed to grain structure inhomogeneity in the plate. Although the reason for the low cycle life for VE11-4 is not clear, the failure did occur outside of the gauge section and thus is a "trend" data point. 


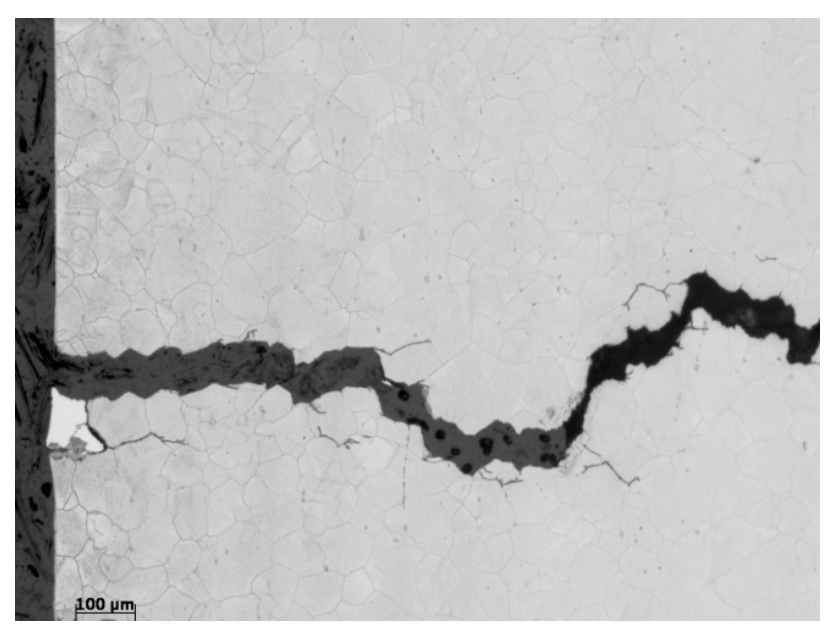

Figure 11. The primary surface crack in the deformed gauge section of creep-fatigue specimen VE11-6.

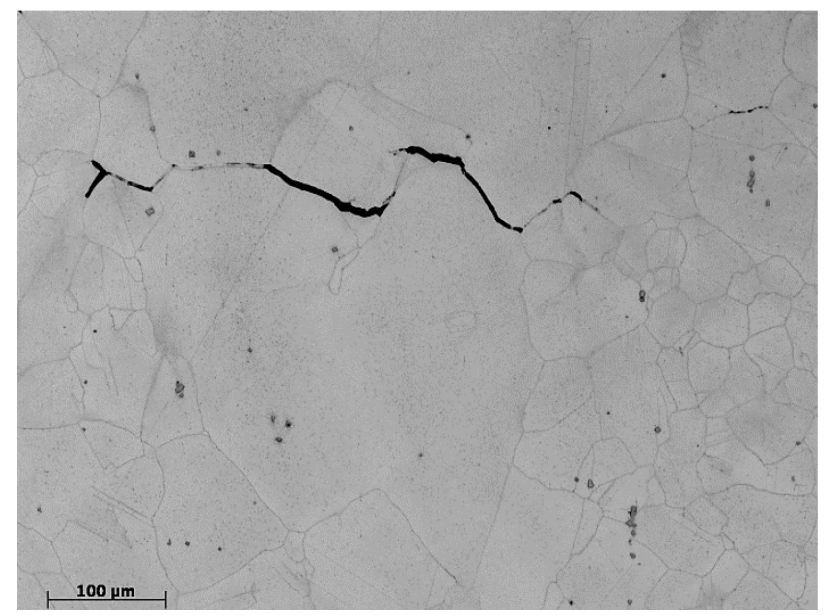

Figure 12. The gauge section of cyclic test specimen VE11-4 illustrating a relatively large grain and interior cracking along the associated grain boundary.

The hypothesis that large grains are detrimental to the creep-fatigue resistance is further supported by a subsequent secondary annealing of $\mathrm{H} 2$ material. Prior to this annealing, the $\mathrm{H} 2$ material exhibited a uniform microstructure with relatively small grains ${ }^{8}$ (large grain size of $80 \mu \mathrm{m}$ ) and the single available creep-fatigue test failed at a relatively long life. Performing a secondary anneal at a high temperature appears to have produced widespread secondary recrystallization (large grain sizes $\sim 600 \mu \mathrm{m}$ ), exhibiting a microstructure predominantly containing large grains (Figure 5). The number of cycles to failure in creep-fatigue was dramatically reduced relative to $\mathrm{H} 2$ without this secondary annealing Figure 8 .

Metallographic images from a longitudinal cross-section of a specimen gauge are provided in Figure 13, which shows cracked grain boundaries in the specimen interior as well as a surface crack that is initially transgranular but quickly transitions to intergranular as it propagates from the surface. 


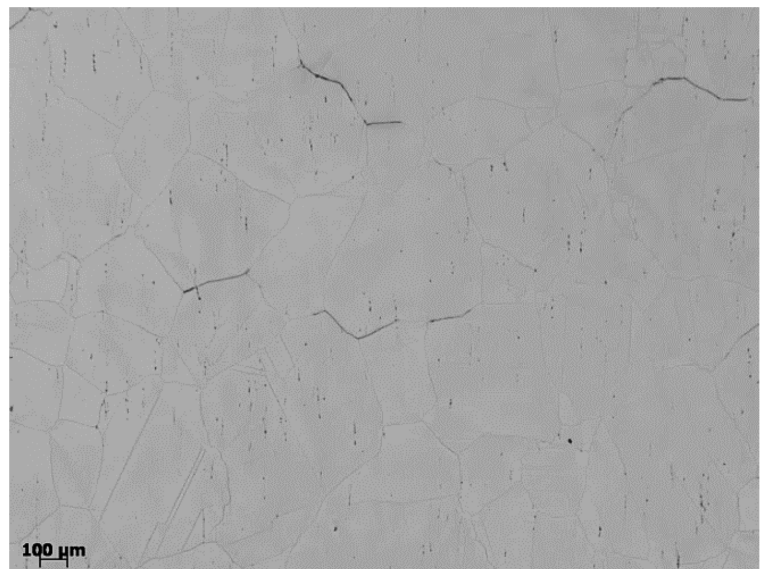

(a)

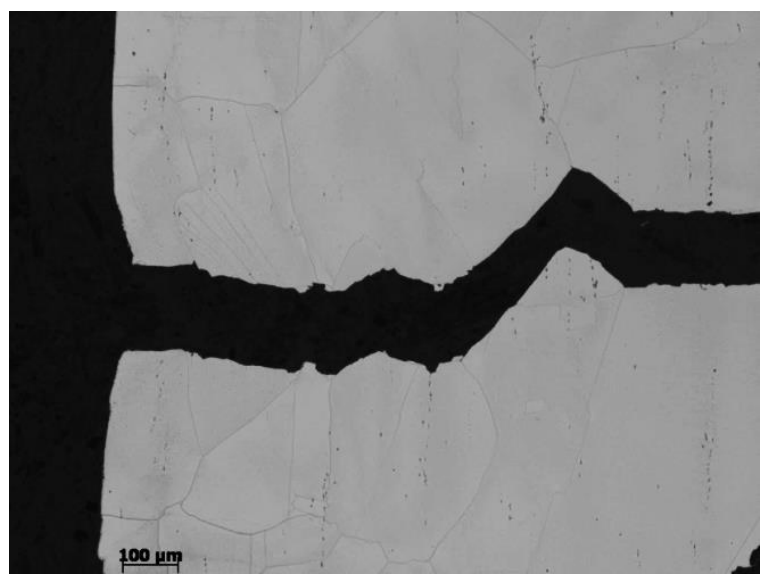

(b)

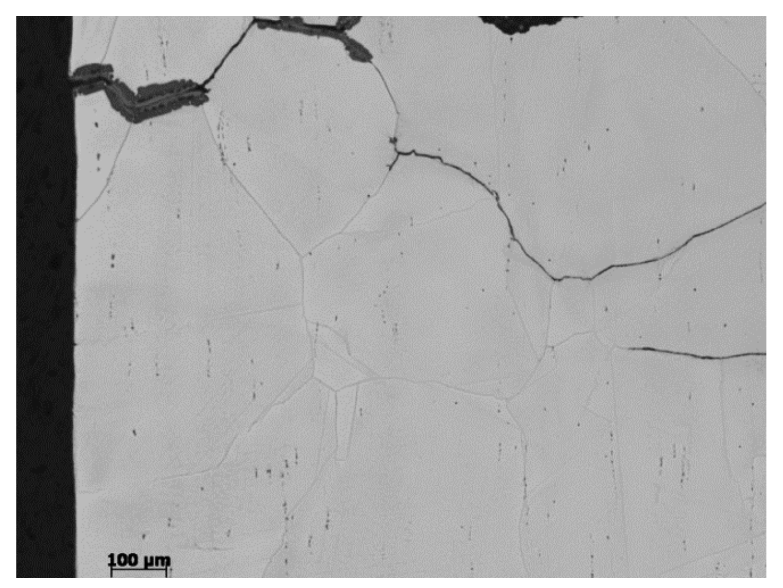

(c)

Figure 13. Optical images of (a) interior grain boundary cracking and (b) (c) surface cracks from the deformed gauge section of creep-fatigue specimen type $\mathrm{H} 2$.

The single creep-fatigue test from plate $\mathrm{F} 2$ exhibited a relatively high $\mathrm{N}_{\mathrm{f}}$, despite the large nonrecrystallized areas present in the specimen (large grain size of $90 \times 700 \mu \mathrm{m}$ for transverse $\times$ tensile axes). The longitudinal specimen cross-section did not show evidence of a large non-recrystallized region; except for an elongated grain that is present just ahead of the secondary surface cracks, as shown in Figure 14(a). Although quite narrow, the imaged portion of the grain extends over $600 \mu \mathrm{m}$ along the specimen axis direction. The grain structure in the area surrounding the primary surface crack, shown in Figure 14(b), appears to be relatively uniform, consistent with the higher creep-fatigue cycle life. Figure 15 shows the specimen from the same heat F2, with a subsequent secondary anneal at high temperatures with a low $\mathrm{N}_{\mathrm{f}}$; in contrast to Figure 14, the grains of Figure 15 are extremely large and the intergranular nature of the propagating crack is evident. The effect of the post-annealing on creep-fatigue life is highlighted in Figure 16. In general, higher temperature additional annealing produced larger grains and shorter lives, with the exception of the two specimens of NP material annealed at a low temperature, NP-4 and NP-5, which were discussed in a previous paragraph. 


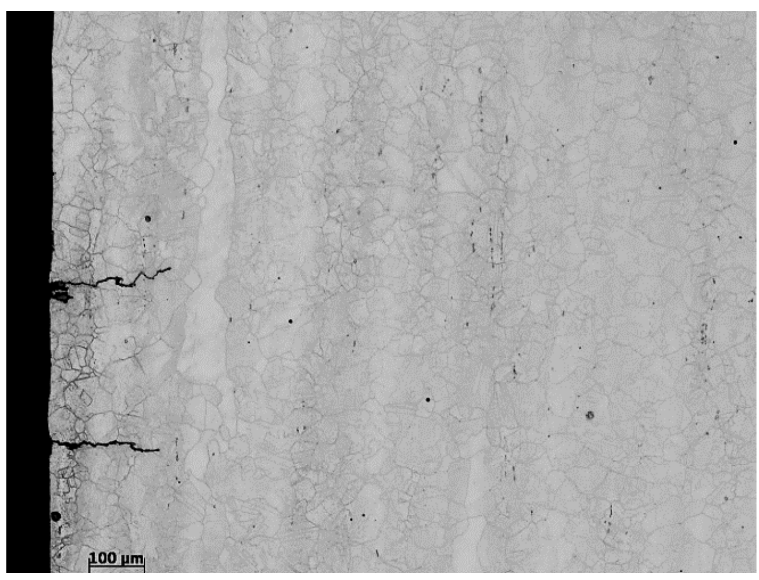

(a)

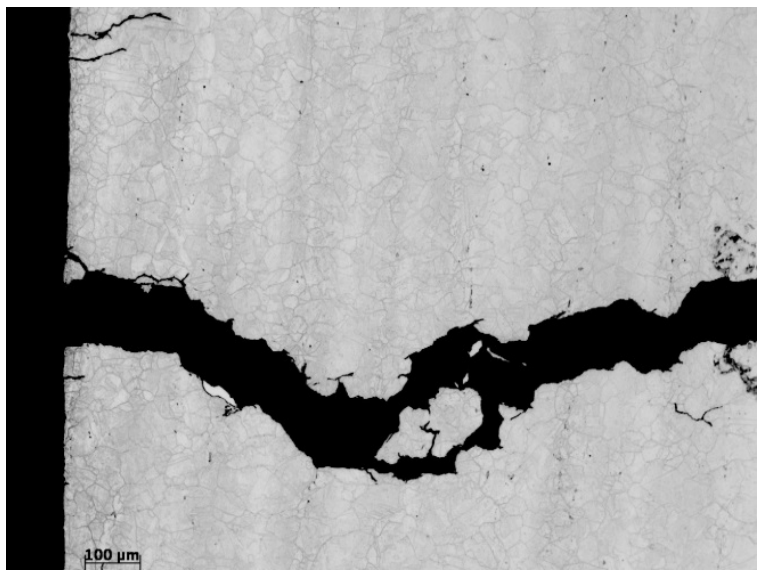

(b)

Figure 14. Longitudinal cross-section from the gauge of deformed creep-fatigue specimen F2-3 illustrating (a) secondary surface cracks and (b) the primary surface crack, as well as the grain structure in the surrounding region.

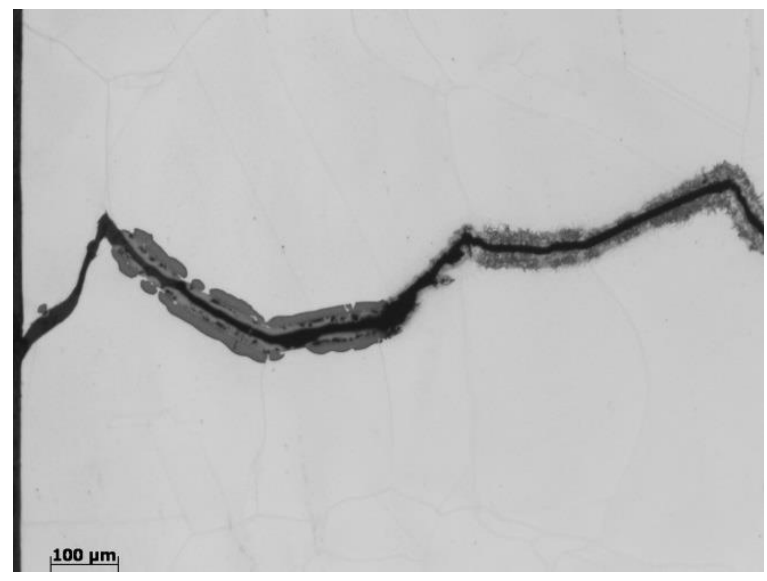

(a)

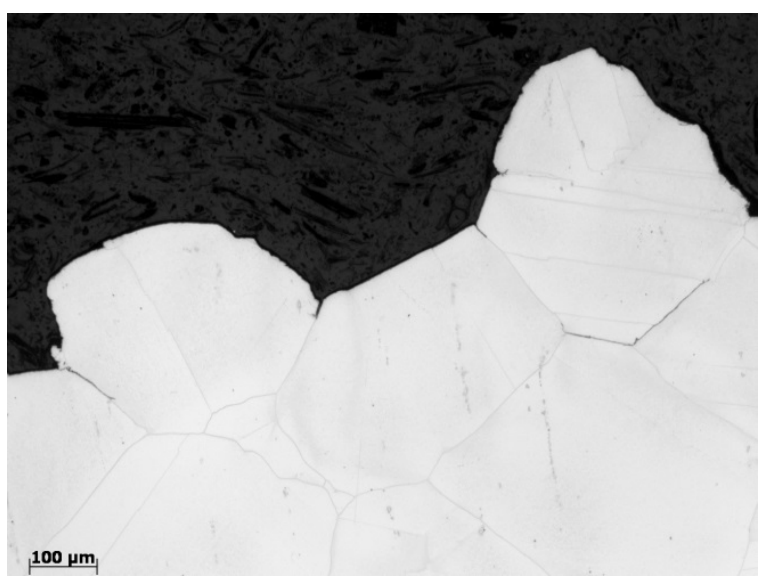

(b)

Figure 15. An image of the longitudinal cross-section from the gauge of deformed creep-fatigue specimen F1150-1 (F2 with an additional high temperature secondary annealing) illustrating the intergranular nature of the crack initiation and propagation. 


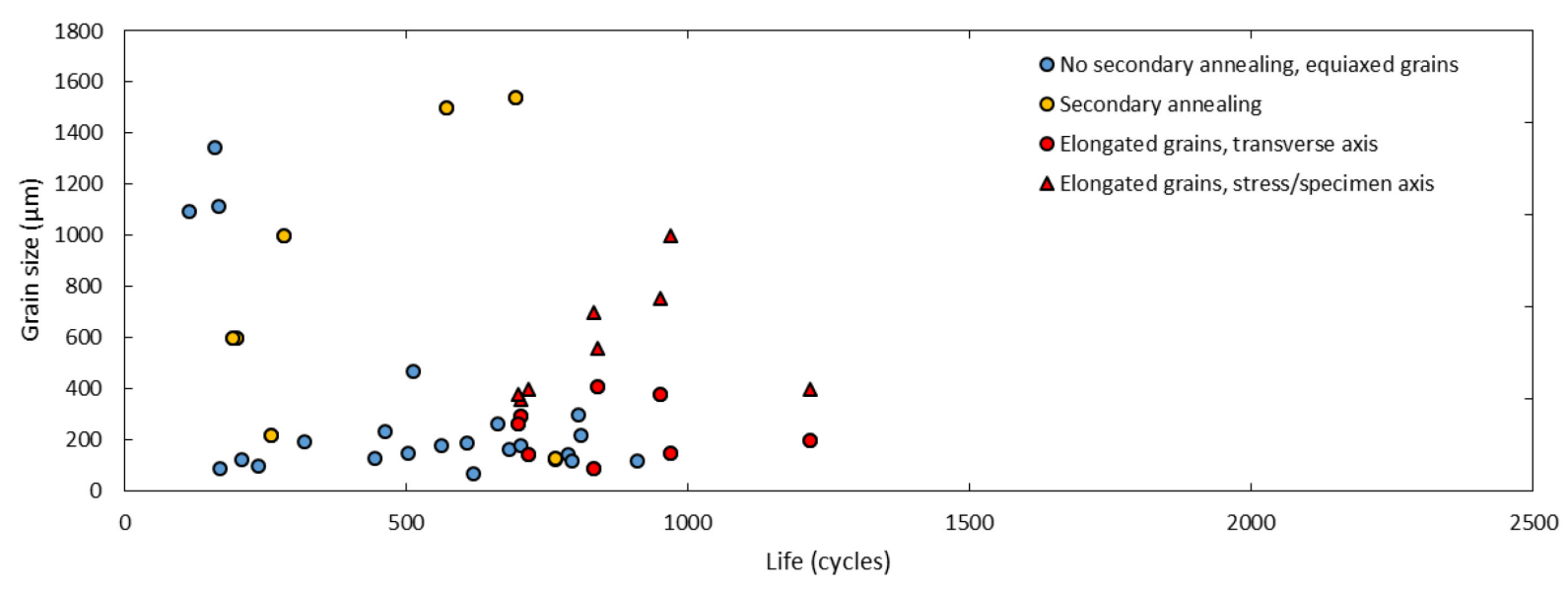

Figure 16. A more detailed breakdown of Figure 9, showing the size effect of the larger grains on creep-fatigue life. Specimens that underwent additional annealing are depicted separately, and the diameters both transverse and parallel to the stress axis are shown for specimens with elongated grains.

Elongated grains (narrow in the axis transverse to the stress axis) did not degrade the creep-fatigue resistance as dramatically as equiaxed large grains presumably because of the manner in which the creep-fatigue testing was conducted. The orientation of the specimen axis relative to the elongated grain diameters $(\sim 300 \times 500 \mu \mathrm{m}$ in the transverse $\times$ tensile axes $)$ in 39A11-A and 39A11-B likely had a role in the longer creep-fatigue cycles to failure than specimens with large equiaxed grains. The elongated grains in Figure 2 have an aspect ratio of over three with the longer dimensions along the specimen axis. The propagating surface cracks travel perpendicular to the stress/specimen axis and thus travel along smaller continuous grain boundary lengths. Figure 16 shows grain measurements in both the specimen axis (elongated) and the transverse axis (short). The specimens with grains elongated along the specimen axis exhibits unusually high fatigue lives for the grain sizes (red triangles in Figure 16); however, the transverse grain measurements (red circles in Figure 16) fall right in line with expected grain size vs. life based on equiaxed grain measurements. This further highlights that the length of the grain along the stress/specimen axis plays little to no role in the creep-fatigue life. The creep-fatigue resistance of longitudinally oriented specimens from plates 39A11, 39X11, 40A11 and 40X11 does not appear to be degraded and is similar to that of specimens with smaller, equiaxed grains (data recorded in Table 1 and Figure 9). The $\mathrm{N}_{\mathrm{f}}$ range from over 600 to nearly 1000 . Additional detail is available in previous reports. ${ }^{1,2}$

To further examine the role of grain structure on creep-fatigue life, cyclic testing of specimens oriented in the transverse orientation was performed, with the specimens cut from same plate as the 539-2 specimens. The fatigue and creep-fatigue lives of these specimens (539-2T-1, 539-2T-2, 539-2T-3, 539-2T-4) was not significantly different from specimens cut in the rolling direction. Micrographs showing etched microstructure of three of the specimens are shown in Figure 17. Note the presence of elongated grains still visible in the microstructure, though there are instances, as shown in Figure 17c of very convoluted grains that are large in both width and length. 


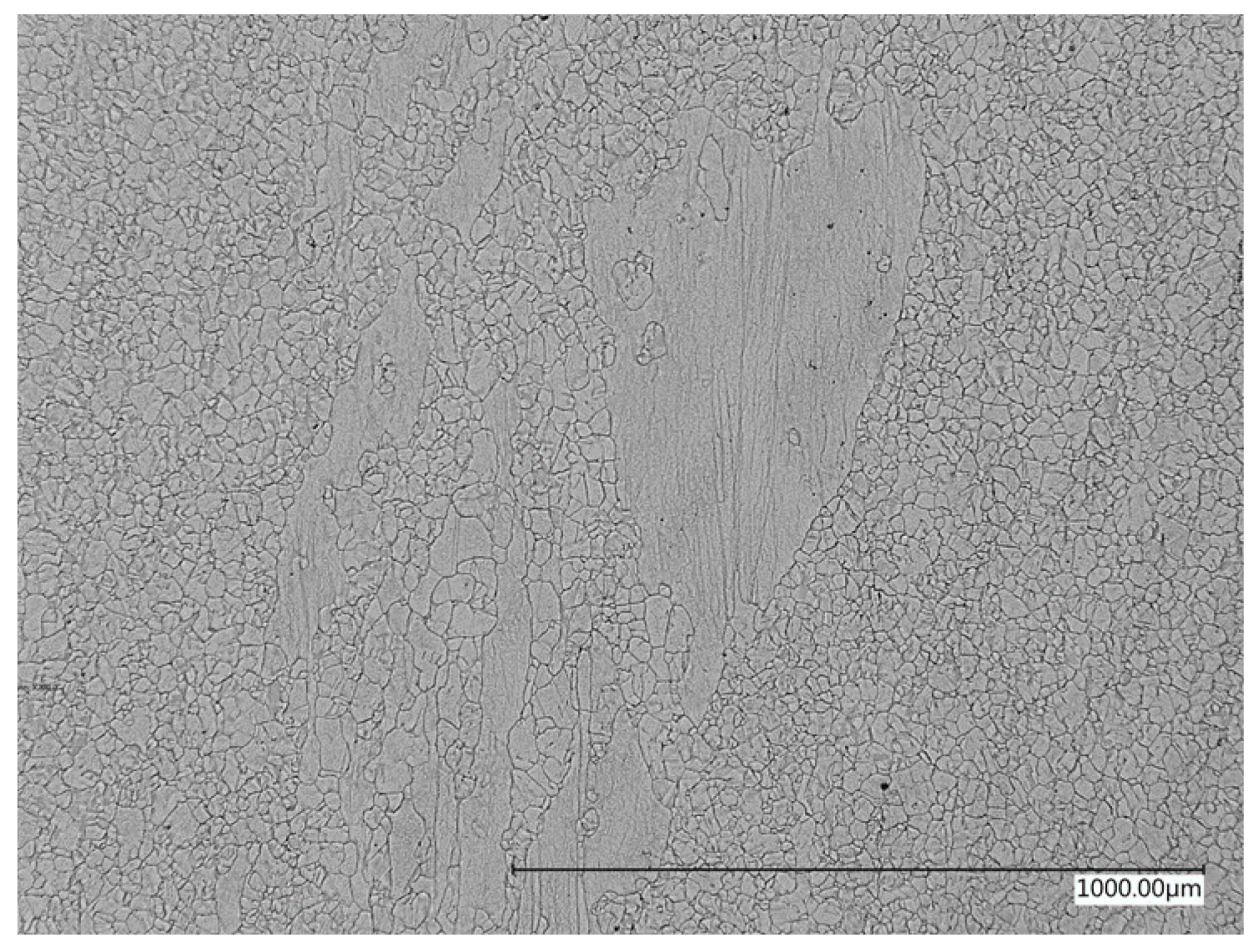

(a)

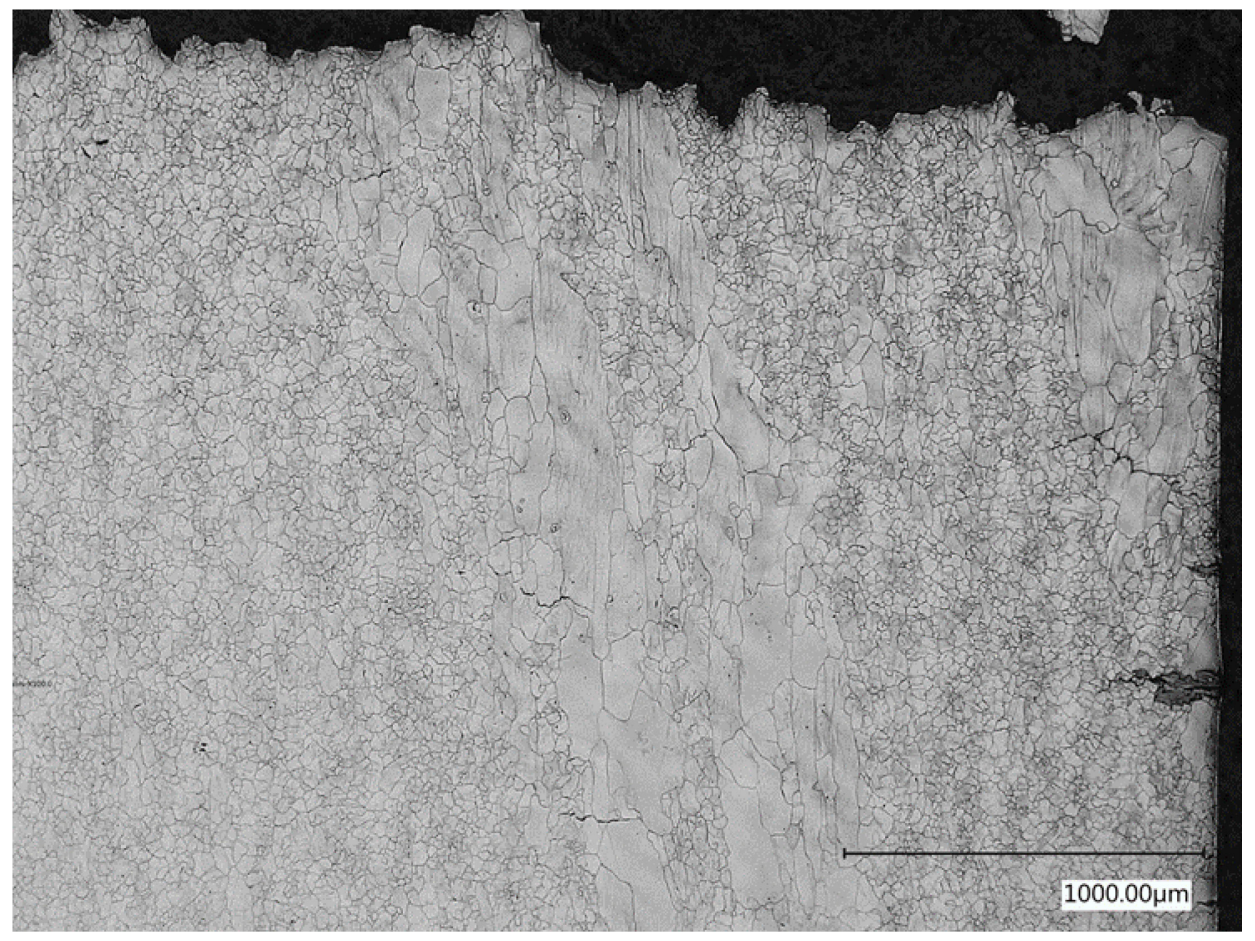

(b) 


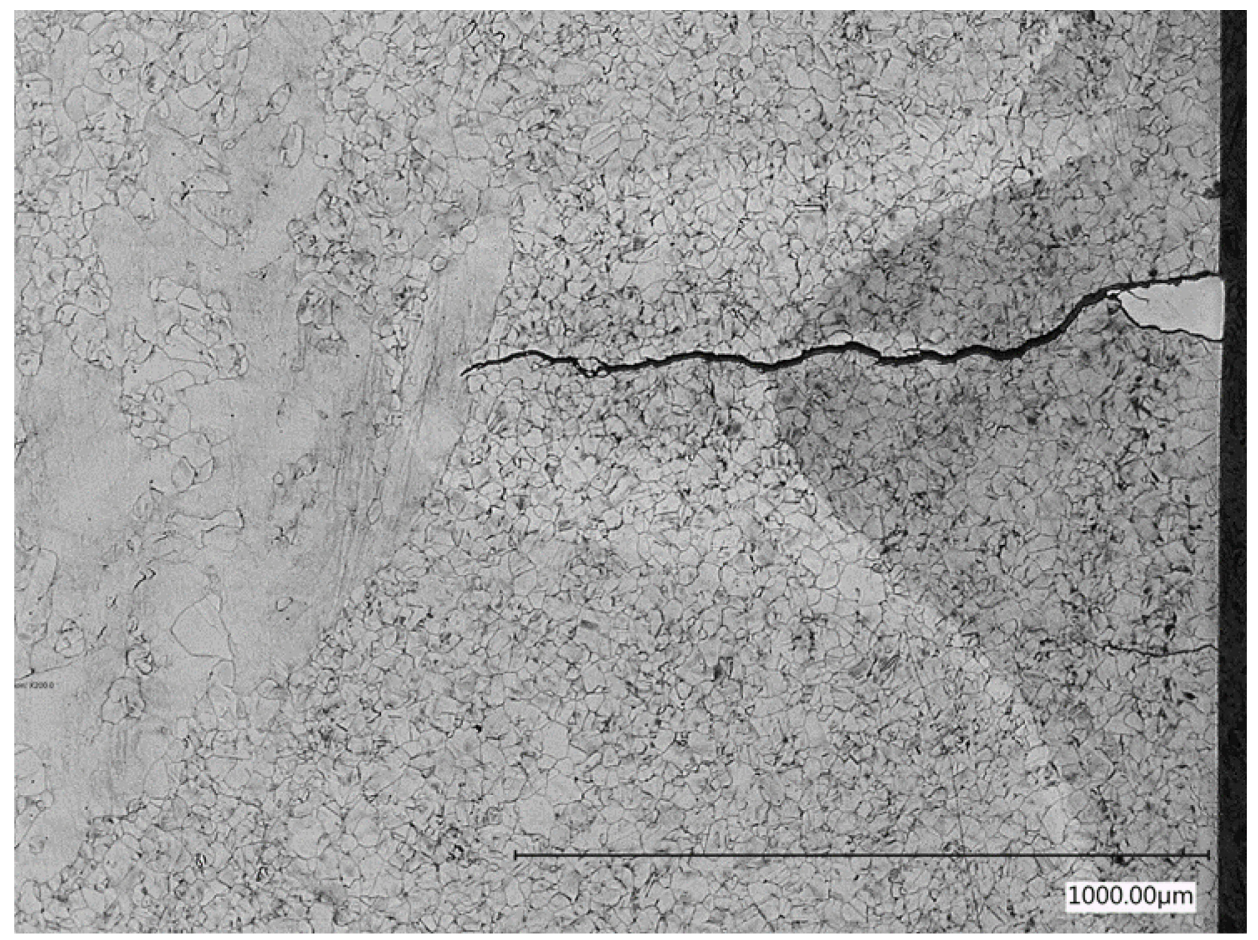

(c)

Figure 17. Micrographs from specimens (a) 539-2T-1, (b) 539-2T-2 and (c) 539-2T-3. Micrographs show cross sections of the gauge section post fatigue/creep-fatigue testing. Loading axis is vertical (up and down on the images)

\subsubsection{Creep-Fatigue: $\mathbf{3 1 6 H}$}

For comparison purposes, specimens machined from $316 \mathrm{H}$ rod were also tested in creep-fatigue at $650^{\circ} \mathrm{C}$ and $1.0 \%$ total strain with a 30 minute tensile hold time. The $\mathrm{N}_{\mathrm{f}}, 856$ and 909 , are plotted as open black triangles in Figure 8. Longitudinal cross-sections of the gauge section revealed that the microstructure in the cyclically deformed specimens does contain some larger grains, as shown in Figure 18 and Figure 19. These large grains with diameters of several hundred microns were present among grains of significantly smaller size. Despite the presence of these larger grains, the creep-fatigue resistance of $316 \mathrm{H}$ was relatively high compared to the 709 specimens with large grains. Figure 20 shows creep-fatigue surface cracks that have propagated from the specimen surface. In the case of Figure 20(b), the crack appears to have initiated at the grain boundary of one of these larger grains. 


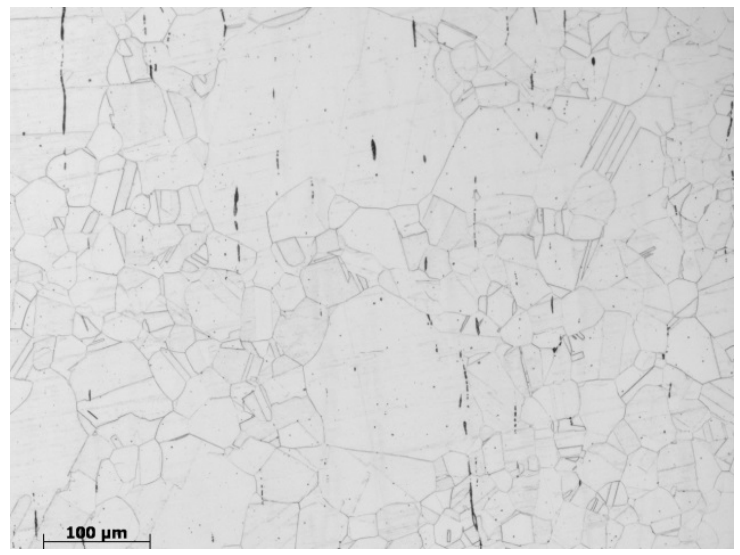

(a)

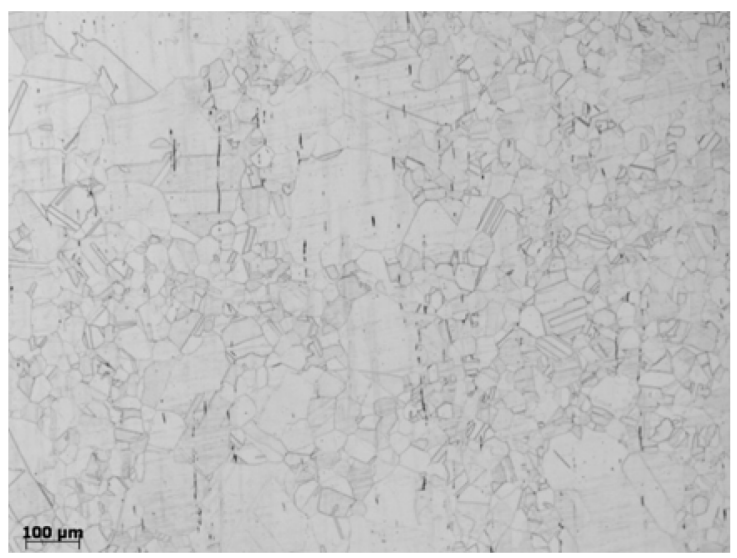

(b)

Figure 18. Grain structure in the grip section of failed $316 \mathrm{H}$ creep-fatigue specimen $76 \mathrm{~B}-3$ illustrating larger grains with the grain structure. The largest grains are over $200 \mu \mathrm{m}$ in diameter.

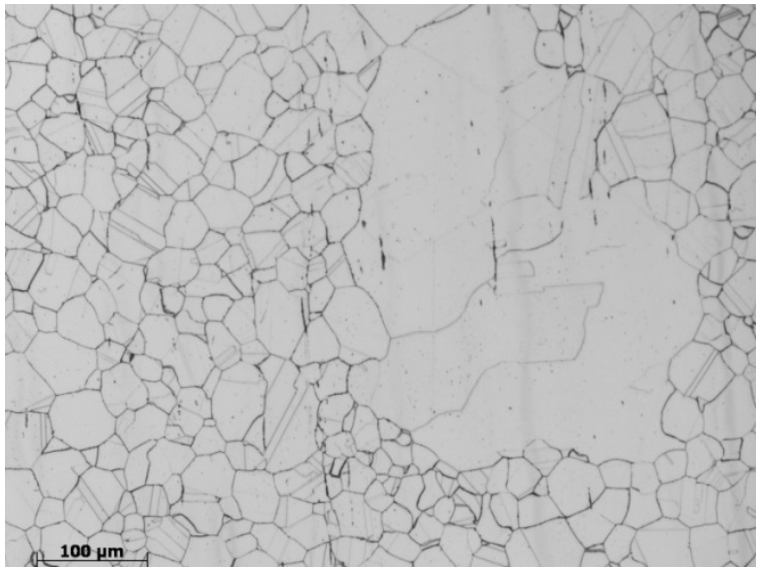

(a)

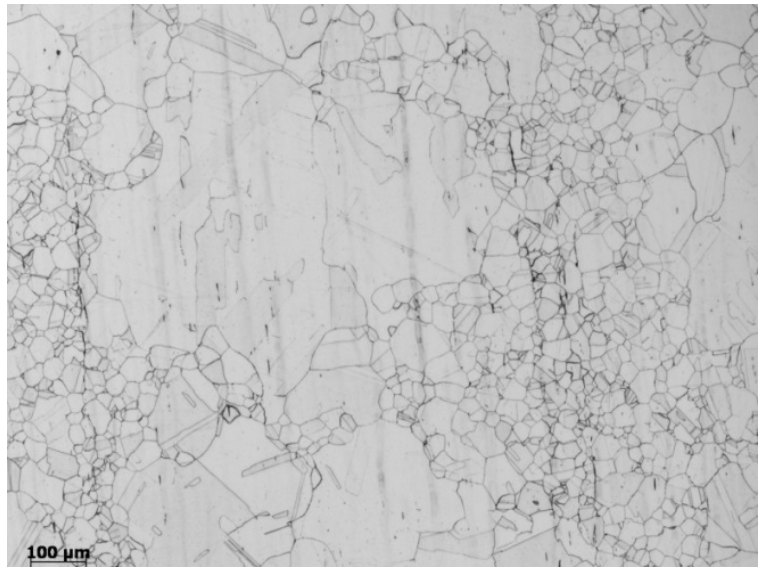

(b)

Figure 19. Larger grains within a bimodal grain structure in the grip section of failed $316 \mathrm{H}$ creep-fatigue specimen 76B-4. The largest grains are over $200 \mu \mathrm{m}$ in diameter. 


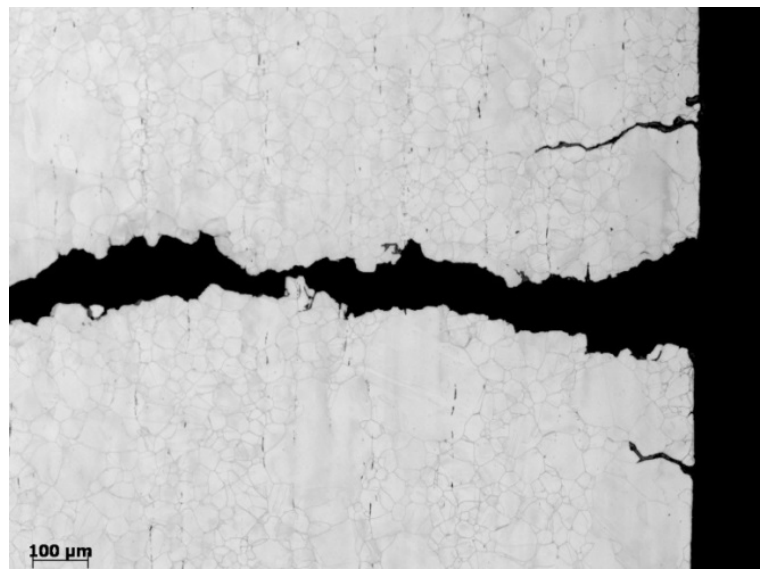

(a)

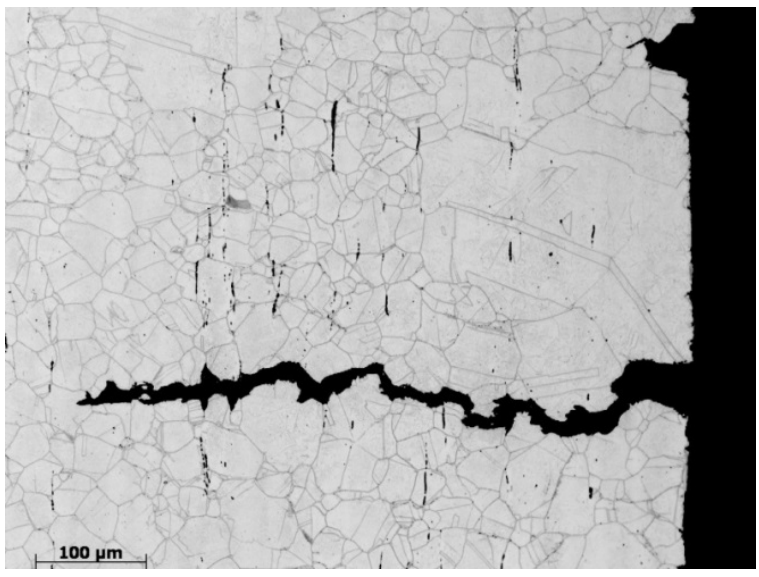

(b)

Figure 20. The microstructure and creep-fatigue cracking in a longitudinal cross-section of the gauge of $316 \mathrm{H}$ cyclic specimens (a) 76B-3 and (b) 76B-4, illustrating cracks that have propagated from the specimen surface.

For Alloy 709, it has been suggested that large grains (larger than $400 \mu \mathrm{m}$ ) may be detrimental to the creep-fatigue resistance and responsible for lower than expected creep-fatigue cycle lives. The logical question is whether this is the case for other austenitic stainless steels. From the minimal amount of data provided herein, it appears that grains with 200 to $300 \mu \mathrm{m}$ grain diameters do not result in a similar reduction in creep-fatigue lives for $316 \mathrm{H}$. Unfortunately, $316 \mathrm{H}$ material with a bimodal microstructure with isolated grains larger than 400 or $500 \mu \mathrm{m}$ is not available. More research is clearly necessary to determine if the creep-fatigue resistance of $316 \mathrm{H}$ is less sensitive to the underlying grain structure than Alloy 709.

Previous testing of cold drawn and hot rolled 316 stainless steels also suggests that $\mathrm{N}_{\mathrm{f}}$ for these test conditions is about $600-1000 .{ }^{13}$ It has been reported by Yamaguchi and Kanazawa ${ }^{19}$ that the creep-fatigue resistance of $316 \mathrm{H}$ is degraded by large grains. They investigated the influence of grain size on the low-cycle fatigue resistance of multiple types of stainless steels. The general trend suggests that the creep-fatigue resistance and slow strain rate fatigue resistance is reduced for low grain size numbers (i.e., large grains). ${ }^{18}$ The number of cycles to failure in creep-fatigue shows a downward trend from a grain size of 9 and drops by almost a factor of 3 for a grain size of 1 , although the data as a function of grain size is not available for a single stainless steel composition. ${ }^{18}$ It should also be noted that a 316 stainless steel heat tested by Brinkman ${ }^{17}$ showed relatively poor creep-fatigue resistance, represented by the lowest 316 creep-fatigue data point in Figure 8. Unfortunately, a microstructural description of this heat of material is not available.

\section{SUMMARY}

In summary, the creep-fatigue testing of multiple heats with multiple sets of processing conditions suggests that very large grains are detrimental to the creep-fatigue resistance of Alloy 709 . However, the inhomogeneity in the grain structures of the Alloy 709 plates makes it particularly difficult to show a definitive association as evidenced by the large amount of scatter in $\mathrm{N}_{\mathrm{f}}$ in plates with isolated regions of secondary recrystallization or incomplete recrystallization. Experiments designed to study the influence of various grain structures, and possible grain boundary constituents, would be beneficial. For example, it is important to determine if the benefit of a lower temperature anneal, is a result of changing phase constituents or just related to its ability to induce a uniform microstructure. The controlling variable is not yet clear. It is possible the grain structure within specific regions of the plates was responsible, such as in the specimens NF, CPR, and NP/VE11. It is unclear if the addition of the lower temperature anneal 
improves creep-fatigue properties or if the material in that region was more homogeneous for the particular specimens tested. The creep-fatigue resistance of the 539 specimens appeared more resilient to the underlying grain structure; however, this may be attributed to the orientation of specimens relative to the elongated grains and the smaller maximum grain size. Presumably, microstructures similar to those observed in Figure 1 for F2 would be detrimental to the cyclic properties if specimens were tested in the transverse orientation. Further, it appears that the large grains induced in H2 (Figure 5) during additional secondary anneal resulted in a clear reduction in creep-fatigue resistance.

Ideally the processing conditions of large industrial-scale heats can be selected such that these extremely large grains are not present in the microstructure of Alloy 709. It is more difficult to establish a grain size that is acceptable for creep-fatigue resistance and one for which a degradation in the creep-fatigue resistance is expected. This work would suggest that grain diameters of less than $400 \mu \mathrm{m}$ may be acceptable and that grain diameters of $400 \mu \mathrm{m}$ and larger are likely detrimental. Further, elongated grain diameters in a particular direction, such as in the plates 39A11, 39X11, 40A11, 40X11 and 539 specimens, were expected to be more detrimental when specimens were cut in the transverse direction, but this was not found to necessarily be the case.

\section{FUTURE WORK (CREEP TESTING)}

Currently, little work has been performed on creep of Alloy 709. This work is forthcoming and specimens are currently being machined for initial testing. These specimens will be tested during the remaining months of FY17. These specimens will be tested at $600{ }^{\circ} \mathrm{C}, 330 \mathrm{MPa}$, and have an expected lifetime of $\sim 1000$ hours, though this lifetime is expected to vary significantly between specimens, depending on the existing microstructure.

\section{REFERENCES}

1 Wright, J., Lillo, T., and Carroll, L., Intermediate Term Creep-Fatigue Testing of Advanced Alloys, INL/LTD-15-36013 (2015) Idaho National Laboratory, Idaho Falls, ID.

2 Carroll, L.J., Benz, J.K., Intermediate-Term Creep-Fatigue Testing of Alloy 709 and Optimized Grade 92, INL/LTD-14-33022 (2014) Idaho National Laboratory, Idaho Falls, ID.

3 Carroll, L.J., Benz, J.K., Intermediate-Term Creep-Fatigue Testing of an Advanced Austenitic Alloy, INL/LTD-13-30219 (2013) Idaho National Laboratory, Idaho Falls, ID.

4 Carroll, M.C., Carroll, M.C., Creep-Fatigue Behavior of Advanced Alloys, INL/LTD-12-26862 Rev. 1 (2012) Idaho National Laboratory, Idaho Falls, ID.

5 Yamamoto, Y, Maziasz, P.J., and Sham T.-L., Report on the Optimization and Testing Results of Advanced Austenitic Alloys, ORNL/TM-2012/401 (2012) Oak Ridge National Laboratory, Oak Ridge, TN.

6 Tan, L., Yamamoto, Y., and Sham, T.-L., Materials Procurement and Related Examinations of Advanced Ferritic-Martensitic and Austenitic Alloys, ORNL/TM-2013/325 (2013) Oak Ridge National Laboratory, Oak Ridge, TN.

7 Tan, L., Yamamoto, Y., Sham, T.-L., FY14 Materials Procurements and Related Examinations of Optimized Grade 92 and Alloy 709 Steels, ORNL/TM-2014/258 (2014) Oak Ridge National Laboratory, Oak Ridge, TN.

8 Yamamoto, Y., Fast Reactor Structural, Alloy 709 Fabrication Scale-Up, Advanced Reactor Technologies Advanced Materials Program Review, Germantown, Maryland, June 7-8, 2016.

9 Creep Fatigue Testing, PLN-3346 Revision 8, INL/MIS-10-18953. 
10 Wareing, J., Creep-Fatigue Behaviour of Four Casts of Type 316 Stainless Steel, Fatigue of Engineering Materials and Structures 4(2) (1981) 131-145.

11 Wood, D.S., Wynn, J., Baldwin, A.B., O’Riordan, P., Some Creep/Fatigue Properties of Type 316 Steel at $625^{\circ} \mathrm{C}$, Fatigue of Engineering Materials and Structures 3 (1980) 39-57.

12 Nakai, T., Motegi, J., Nakmura, T., Asada, Y., Effect of Air Environment on Creep-Fatigue Interaction of 316 FR Stainless Steel, JSME International Journal 41 (1998) 149-155.

13 Carroll, M.C., Carroll, L.J., Fatigue and Creep-Fatigue Deformation of an Ultra-Fine Precipitate Strengthened Advanced Austenitic Alloy, Materials Science \& Engineering A 556 (2012) 864-877.

14 Holmstrom, S., Pohja, R., Nurmela, A., Moilanen, P., Auerkari, P., Creep and Creep-Fatigue Behaviour of 316 Stainless Steel, Procedia Engineering 55 (2013) 160-165.

15 Kim, D.W., Chang, J.H., Ryu, W.S., Evaluation of the Creep-Fatigue Damage Mechanism of Type 316L and Type 316LN Stainless Steel, International Journal of Pressure Vessels and Piping 85 (2008) 378-386.

16 Takahashi, Y., Shibarnoto, H., Inoue, K., Study on Creep-Fatigue Life Prediction Methods for Low Carbon Nitrogen Controlled 316 Stainless Steel, Nuclear Engineering and Design 238 (2008) 322-335.

17 Brinkman, C., Elevated Temperature Mechanical Properties of an Advanced Type 316 Stainless Steel, Journal of Pressure Vessel Technology 123 (2001) 75-80.

18 Yamaguchi, K., Kanazawa, K., Effect of Strain Wave Shape on High Temperature Fatigue Life of a Type-316 Steel and Application of the Strain Range Partitioning Method, Metallurgical Transactions A 11 (1980) 2019-2027.

19 Yamaguchi, K., Kanazawa, K., Influence of Grain Size on the Low-Cycle Fatigue Lives of Austenitic Stainless Steels at High Temperatures, Metallurgical Transactions A 11 (1980) 1691-1699. 